No $1998-10$

Octobre

ET D'INFONHATIONS

INTER N T TONALE:

Compétitivité et régimes de change en Europe centrale

Michel Aglietta Camille Baulant Virginie Coudert 


\section{TABLES DES MATIÈRES}

SUMMARY

2. LES TAUX DE CHANGE RÉELS DES TROIS PAYS DE L'EST ..................... 9

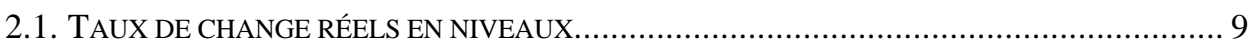

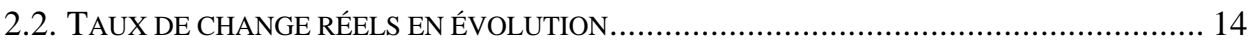

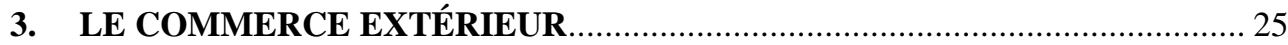

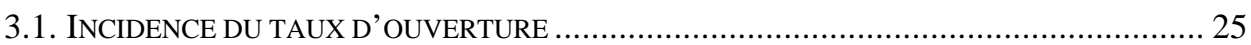

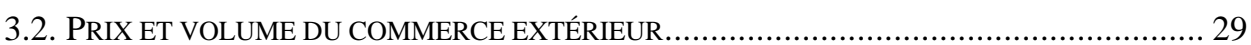

3.3. SITUATION DES TROIS PAYS VIS-À-VIS DU TAUX D'OUVERTURE ................................. 40

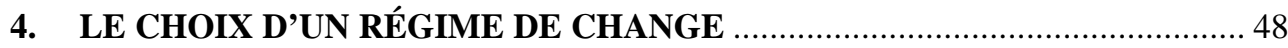

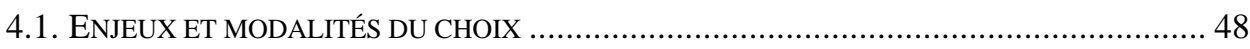

4.2. RÉGIME DE CHANGE ET TENSIONS INFLATIONNISTES ........................................... 50

4.3. RÉGIME DE CHANGE ET BALANCE COMMERCIALE ................................................ 53

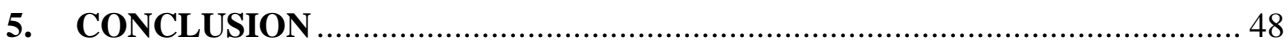

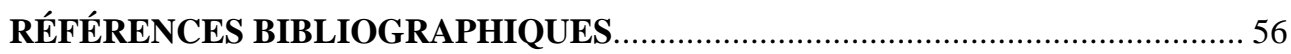

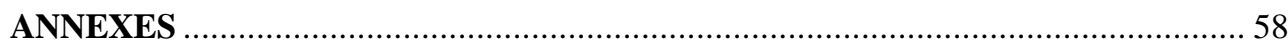

LISTE DES DOCUMENTS DE TRAVAIL DU CEPII ........................................... 65 


\section{SUMMARY}

Hungary, the Czech Republic and Poland are countries which were successful in stabilizing their economies early in the decade. It is why the process of modernizing their economic structure is well under way. The three governments have been reforming their open economies in the prospect of integrating the European Union. The medium-term performance of the three economies is studied regarding the relationships between growth, opening to foreign trade and competitiveness.

The ratio of foreign trade to GDP is chosen as a synthetic indicator of modernization, the real exchange rate as a measure of competitiveness. A model is built linking both variables to growth ans to the trade balance in percent of GDP. By estimating the structural relations and simulating the impact of real exchange rate changes on internal and external equilibrium, the three economies can be compared.

Measuring the level and the evolution of real exchange rates enables to surmise a trend appreciation at the possible exception of Hungary. This trend comes from a rising productivity in the modern sectors and a relative price structure getting closer to that of Western countries.

The structural differences between the three countries as regard to the effect of real exchange rate changes in the model are rooted into price and foreign trade functions on the one hand, the degree of nominal wage rigidity on the other hand. Because Poland has a low price elasticity of exports, the impact of a real exchange rate depreciation on both the growth rate and the trade balance is mitigated compared to the other countries. Hungary and the Czech Republic differ from import price adjustment to domestic competition. It follows that a devaluation of the same percentage delivers terms of trade improvement in Hungary and terms of trade deterioration in the Czech Republic and in Poland. Finally nominal wage rigidity looks close to full indexation in the Czech Republic, less so in Hungary and chiefly Poland who has benefited from an income policy.

These economic features bring about a dilemma between disinflation and competitiveness, familiar to ermerging countries. Inflation is subdued but is still well above the excessively low standard of EMU countries. The inflation rates in the three countries are sustainable in the sense that they entail profit margins high enough to finance domestic investment without undue resort to foreign capital inflows. Slowly decreasing inflation rates with productivity increases are compatible with trendwise equilibrium real exchange rates. The task of exchange rate policy is to hamper the overshooting around fundamental values. Therefore regulated regimes are to be recommended, be they a managed float or a sliding fluctuation band with wide margins. Because capital inflows are too sensitive to a steep rise in interest rates, it is the duty of fiscal and eventually income policy to smooth pent-up demand pressures. 


\section{RÉSUMÉ}

La Hongrie, la République tchèque, la Pologne ont réussi leur stabilisation nominale tôt dans la décennie et sont bien engagées dans la modernisation de leurs structures. $\mathrm{Ce}$ processus est conduit dans des économies ouvertes et dans la perspective de l'intégration à l'Union européenne. On étudie les performances de ces trois pays dans une approche macroéconomique qui s'intéresse aux conditions de la croissance à moyen terme.

On choisit le degré d'ouverture au commerce international comme indicateur synthétique de la modernisation des structures productives et le taux de change réel comme expression de la compétitivité. On construit un modèle qui relie le degré d'ouverture et le taux de change réel aux variables représentant l'équilibre interne (la croissance réelle) et l'équilibre externe (la balance commerciale rapportée au PIB). On compare les structures des trois pays en estimant les relations du modèle et en simulant l'impact de la variation du taux de change réel sur le double équilibre.

La mesure du taux de change réel en niveau et en évolution permet de conjecturer une appréciation tendancielle, sauf peut-être en Hongrie, au fur et à mesure que la productivité augmente dans les secteurs modernisés et que la structure des prix relatifs dans ces économies se rapproche de celle des pays auxquels elles s'intègrent.

L'estimation des relations entre les prix et les fonctions du commerce extérieur d'une part, la simulation d'autre part, permettent de repérer les différences entre les trois pays. La Pologne a une faible élasticité-prix des exportations de sorte que sa croissance est moins stimulée et sa balance commerciale moins améliorée que celles des deux autres pays pour une même dépréciation réelle du taux de change. La Hongrie et la République tchèque se distinguent par les différences d'intensité de concurrence sur les marchés intérieurs. Il s'ensuit que pour une même dévaluation, les termes de l'échange s'améliorent en Hongrie, alors qu'ils se détériorent en République tchèque et en Pologne. Enfin, la répercussion d'une variation nominale du taux de change sur les prix intérieurs dépend de l'indexation entre salaires et prix. La rigidité nominale parait très élevée en République tchèque, moins importante dans les deux autres pays, surtout en Pologne où une politique de revenus a été mise en place.

Les caractéristiques macro-économiques se traduisent par un dilemme entre désinflation et compétitivité qu'on retrouve dans nombre de pays émergents. L'inflation est sous contrôle, mais elle est fort au dessus de la norme excessivement basse des pays de l'Union européenne. Ces taux d'inflation sont compatibles avec les profits qui permettent de financer l'investissement intérieur sans recours excessif aux entrées de capitaux. La politique de change doit donc éviter des cycles de sous-évaluation et de surévaluation autour d'une tendance du taux de change réel qui résulte des progrès de productivité et de la convergence de la structure des prix relatifs vers celles des pays de l'Union européenne. Cela incite à recommander des régimes de change de flottement géré ou de glissement d'une bande de fluctuation large. Comme les entrées de capitaux sont trop sensibles aux hausses de taux d'intérêt, il revient aux politiques budgétaires et éventuellement à des politiques de revenu de calmer la pression de la demande excédentaire. 


\title{
Compétitivité et régime de change en Europe Centrale
}

\author{
Michel Agliettal ${ }^{1}$, Camille Baulant ${ }^{2}$ et Virginie Coudert ${ }^{3}$
}

\section{INTRODUCTION}

Les PECO ont connu une forte augmentation du taux d'ouverture de leur commerce extérieur concurrentiel après l'effondrement du commerce planifié de la CAEM et la réorientation forcenée vers la zone OCDE.

L'ouverture d'une économie a des incidences multiples. Elle rend les prix intérieurs plus sensibles aux variations des prix internationaux et du taux de change. $\mathrm{La}$ dépréciation du taux de change peut ainsi déclencher plus rapidement et plus complètement des répercussions inflationnistes qui détruisent les gains transitoires de compétitivité.

Cependant, lorsque les échanges extérieurs représentent une part de plus en plus grande de la production, une dévaluation a un effet direct accru sur la demande, contrecarrant celui qui découle de l'érosion des gains de compétitivité dus à l'inflation. Si la stimulation de la croissance ne s'accompagne pas d'une augmentation parallèle des capacités de production compétitives, la pénétration du marché intérieur par les importations est favorisée. L'accroissement de l'ouverture de l'économie s'entretient de luimême, mais le surplus exportable se réduit sous le double effet de l'érosion de la compétitivité-prix et de la tension sur les capacités de production.

On peut donc s'attendre à une double incidence favorable puis défavorable sur la balance commerciale. Ce second effet incite à une dépréciation continue du taux de change pour éviter de creuser le déficit. Encore faut-il que cette dépréciation ne provoque pas des répercussions inflationnistes de plus en plus complètes et de plus en plus rapides. A l'égard de ces processus les trois pays étudiés ont connu des fortunes diverses depuis 1993, époque à partir de laquelle la stabilisation est accomplie. Le choc récessif initial, plus ou moins fort selon les pays, a fait place à une reprise plus ou moins vive de la croissance du PIB. Cette reprise a entraîné une forte détérioration des balances commerciales. En 1992, les balances étaient équilibrées en Hongrie et en Pologne. En 1997, le déficit était de 6\% du PIB environ en Hongrie et de 10,5\% en Pologne. En 1993, la balance commerciale était

\footnotetext{
${ }^{1}$ CEPII et Mini-Forum Université de Paris X-Nanterre.

2 GEAPE, Université d'Angers.

${ }^{3}$ Banque de France, Direction des changes. Les vues exprimées dans ce texte n'engagent pas la Banque de France.
} 
légèrement excédentaire en République tchèque. En 1997 le déficit atteignait 10\% après une pointe au-delà de $10 \%$ en 1996. Dans chacun de ces pays, on peut observer les relations entre la demande interne, la balance commerciale et le taux de change.

En Hongrie, la détérioration de la balance commerciale a été très brutale en dépit d'une économie peu dynamique, mais où la consommation en volume avait relativement peu reculé (pas plus de 10\%) dans la phase initiale de stabilisation. Pourtant le déficit commercial extérieur s'est creusé de 10\% entre 1992 et 1994. Parallèlement le forint s'était fortement apprécié en termes réels contre le dollar en 1994, sous le double effet d'une réévaluation nominale consécutive à la baisse du dollar contre les monnaies européennes et d'une accélération de la hausse des prix. Ces tensions ont justifié une dévaluation du forint au début de 1995, couplée à une politique d'austérité qui a fait baisser la consommation et l'investissement privés en 1995. La double incidence de l'amélioration de la compétitivité et de la baisse de l'absorption a été conforme à une réponse normale du commerce extérieur : amélioration de la balance qui est passée d'un déficit de $10 \%$ en 1994 à 6\% en 1998. Ensuite une gestion du change selon une dépréciation régulière du forint (crawling peg) et une demande intérieure contenue ont stabilisé le déficit commercial, tout en autorisant une lente reprise. La maîtrise de la contrainte extérieure par un régime de croissance faible a, bien sûr, l'inconvénient de ralentir le changement des structures de production à travers l'investissement productif. Celui-ci ne progresse que très lentement. Il faut toutefois noter que la Hongrie a attiré les investissements directs étrangers qui peuvent être porteurs de changements qualitatifs pour l'insertion du pays dans les échanges internationaux.

En République tchèque, les évolutions ont été très différentes. La croissance y a été fortement déséquilibrée avec une vive reprise parallèle de la consommation et de l'investissement privé (celui-ci ayant presque doublé en volume de 1993 à 1997). En même temps le taux de change était resté fixe en terme nominal contre un panier composé de $60 \%$ de mark et de $40 \%$ de dollar. Malgré une inflation stabilisée autour de 10\% depuis 1994, c'est à dire en moyenne deux fois plus faible que celle de la Hongrie, l'appréciation réelle du taux de change a été vive puisque le taux de change nominal était fixe. Certains auteurs (Halpern et Wyplosz notamment) ont soutenu que c'était un mouvement d'équilibre sous l'effet de l'augmentation de la productivité et du rattrapage des salaires très bas dans les services. Il n'empêche que la balance commerciale s'est dégradée d'une manière foudroyante, passant d'un excédent de $1 \%$ en 1993 à un déficit de 10\% en 1996. Au premier trimestre 1997 la couronne tchèque a subi une crise de change déclenchée par l'inquiétude des investisseurs étrangers devant le profil insoutenable des comptes extérieurs, d'autant que la balance courante évoluait parallèlement à la balance commerciale. La chute très forte de la monnaie dans les premiers mois de 1997 a convaincu la banque centrale d'abandonner l'ancrage nominal et de passer à un régime de flottement contrôlé. Néanmoins la crise de change a laissé des traces en relançant quelque peu l'inflation de 6 à 10\% par an. Le rythme de croissance a subi un sérieux coup de frein (4,5\% en 1996 et $1,5 \%$ en 1997) et la balance commerciale a commencé à se redresser.

La Pologne a choisi un régime de change de crawling peg contre un panier de mark et de dollar. Cette dépréciation contrôlée d'environ $1 \%$ par mois du zloty n'a pas 
empêché le pays de mener une désinflation régulière. Le taux d'inflation en rythme annuel dépassait $50 \%$ au début de 1992. Il a été ramené à 13\% environ fin 1997. Pourtant la Pologne poursuit une croissance rapide dans laquelle la demande globale, surtout l'investissement privé, s'est emballée, depuis 1995 avec la dépréciation du zloty. La conséquence a été une détérioration continue de la balance commerciale depuis 1992. De l'équilibre après la stabilisation initiale, le déficit est monté à $5 \%$ en 1993 . Après une stabilisation sur ce plateau pendant deux ans, la dégradation s'est précipitée pour atteindre près de $11 \%$ en 1997 sur une tendance toujours poursuivie. La surchauffe par l'investissement, financé par le crédit lui-même nourri par les importations de capitaux, menace la Pologne. Ce qui est intéressant dans ce déséquilibre est le creusement du déficit extérieur en dépit d'une compétitivité-prix à l'exportation qui est restée stable depuis 1994. La politique monétaire restrictive a élevé les taux d'intérêt pour calmer l'emballement de la demande intérieure. Mais elle a attiré des capitaux étrangers qui ont permis aux banques de financer une offre de crédit plus importante, ce qui entretient la demande intérieure. Cependant l'évolution du taux de change réel s'est retournée dans le sens de l'appréciation. Si elle parvient à être contrôlée dans le cadre de marges élargies pour le taux de change nominal, un ralentissement ordonné de l'expansion est possible.

Cet examen rapide des conditions réelles de la transition dans la phase poststabilisation montre que les trois pays sont soumis à la contrainte extérieure. Car la transition de ces pays s'inscrit dans la tendance à une forte augmentation du degré d'ouverture au commerce international concurrentiel. La transformation des structures productives de ces pays, l'incorporation du progrès technique, sont des facteurs d'efficacité économique, source de croissance, qui sont guidés par leur insertion dans la division internationale du travail. Mais ces changements structurels ne peuvent s'accomplir régulièrement et progressivement que si les relations macro-économiques résultant de la formation des prix et des revenus, de l'investissement intérieur et du commerce extérieur, aboutissent à des équilibres macro-économiques évolutifs mais soutenables. Ces équilibres sont influencés par les politiques économiques dans la mesure principalement de leur influence sur le taux de change. L'objectif de cette étude est de caractériser les expériences des trois pays du point de vue des interactions entre les changements structurels et les ajustements macro-économiques.

Le reste du papier s'organise comme suit. Dans la partie (II) on analyse le taux de change réel en niveau et en évolution. La mesure en niveau permet de souligner la sousévaluation des monnaies à la sortie de la période de stabilisation. Tenir compte de ces conditions initiales est important pour interpréter l'évolution des prix dans la phase suivante de la transition. L'augmentation du degré d'ouverture entrâne une adaptation des prix intérieurs à la concurrence internationale. La structure des prix relatifs se transforme ; ce qui permet de comparer différentes mesures de la compétitivité dans les trois pays.

La partie (III) étudie le commerce extérieur et son rôle sur les équilibres internes et externes. L'augmentation du degré d'ouverture est choisie comme indicateur du rythme des changements structurels. On construit d'abord un modèle pour étudier l'influence du degré d'ouverture sur la relation entre la croissance et la variation du taux de change réel d'une part, la balance commerciale et la variation du taux de change réel d'autre part. Ces 
relations dépendent de paramètres structurels qu'il faut estimer. Ces estimations sont faites systématiquement pour les trois pays. On traite la formation des prix conformément aux équations du modèle : détermination des prix à l'importation et à l'exportation, relations entre prix intérieurs et coûts salariaux. Puis on estime les fonctions du commerce extérieur pour évaluer les élasticités-prix et revenus des volumes d'exportation et d'importation. Les valeurs numériques estimées ou présupposées pour l'ensemble des paramètres structurels du modèle permettent de simuler l'incidence de l'augmentation du degré d'ouverture dans les trois pays. On peut caractériser les facteurs structurels qui les distinguent et réfléchir aux conséquences de ces disparités pour le choix des régimes de change.

La partie (IV) s'intéresse d'abord au type de régime de change : flexibilité, ancrage ou régime intermédiaire. Compte tenu des plus ou moins grandes rigidités dans la détermination des prix, des contraintes extérieures et des réactions aux changements de la compétitivité, des recommandations peuvent être faites pour concilier tant que faire se peut trois objectifs : poursuivre la désinflation, rétablir des balances courantes soutenables, préserver la croissance pour continuer à adapter les structures de production à des taux d'ouverture élevés. La monnaie d'ancrage pour une zone cible ou de référence pour une gestion du flottement serait avantageusement l'euro après l'adhésion des trois pays à l'Union Européenne. Une conclusion (V) tire les conséquences de l'étude du point de vue de la politique économique.

\section{LES TAUX DE CHANGE RÉELS DES TROIS PAYS DE L'EST}

\subsection{Taux de change réels en niveaux}

Il s'agit d'étudier le degré de convergence des niveaux de prix vers les pays les plus développés, comme ceux de l'Union européenne, ainsi que l'ajustement des prix relatifs dans ces économies.

La convergence des niveaux de prix dans ces pays s'est effectuée en trois étapes. Tout d'abord, la libéralisation des prix dans ces économies a entraîné des hausses de prix brutales. Plusieurs raisons ont été avancées, notamment la libéralisation des prix de certains produits (hors produits de première nécessité et hors prix des logements) et la surabondance de liquidité initiale. La libéralisation des prix s'est accompagnée de grandes augmentations du taux d'inflation qui ont entraîné des fortes dévaluations. La sousévaluation des monnaies de ces pays, après les dévaluations opérées dans le cadre des programmes de stabilisation, a ainsi renforcé la faiblesse des niveaux de prix de ces pays en monnaie internationale. Dans un deuxième temps, sous l'effet de la concurrence internationale, les prix du secteur exposé ont commencé à converger vers ceux des pays développés. Enfin dans un dernier temps, les prix des services devront aussi converger à la hausse vers ceux des pays à économies de marchés ayant un même niveau de revenu. Les prix relatifs des services étant en effet beaucoup plus faibles que ceux du secteur exposé, l'effet de rattrapage sera encore plus marqué. La convergence totale des niveaux de prix à la consommation (ou des prix du PIB) vers ceux des pays les plus développés n'est pas à attendre cependant avant le moyen ou long terme. 


\section{LES ÉVÉNEMENTS MARQUANTS CONCERNANT LES TAUX DE CHANGE}

\section{Hongrie :}

Ancrage du forint sur un panier à 50\% de dollar et 50\% de DM au début des années 1990. Il a évolué ensuite à $30 \%$ dollar et $70 \%$ DM.

Régime de change :

- ajustable jusqu'en 1995.

- Dévaluation en mars 1995 puis crawling peg à dépréciation de 1,9\% par mois, puis $1,3 \%$ par mois.

- Depuis janvier 1998, une zone cible glissante à dépréciation de 0,9\% par mois avec des marges de fluctuation de $+1-2,25 \%$.

\section{République tchèque :}

Dévaluation initiale de 48,9\% par rapport au dollar en 1990.

Stabilité nominale de 1991 au début 1997 par rapport à un panier de monnaie à 40\% dollar et 60\% DM. Les marges de fluctuation sont à +/- 0,5\% jusqu'au début 1996.

En février 1996, élargissement des marges de fluctuation à +/- 7\% pour contrecarrer les pressions des entrées de capitaux. Très forte appréciation réelle et inversion des mouvements de capitaux au ler trimestre 1997.

Attaque spéculative et disparition du peg le 28 mai 1997.

Modification du panier à $35 \%$ de dollar et $65 \%$ de DM

Passage au flottement géré contre le DM en mai $1997 .$.

\section{Pologne :}

Réforme monétaire et établissement d'un taux de change fixe contre le dollar le ler janvier 1990.

En octobre 1991, établissement d'un crawling peg contre un panier à $45 \%$ de dollar et $55 \%$ de monnaies européennes. Le taux de dépréciation du zloty était de 1,8\% par mois.

Ce régime de change a été conservé, mais les modalités opératoires en ont été infléchies : D'octobre 1995 à la fin février 1998, le taux de dépréciation mensuelle contrôlé a été ramené progressivement de $1,8 \%$ à $1 \%$ par mois. A cette époque, il a été fixé à $0,8 \%$.

Pour combattre les pressions spéculatives, les marges de fluctuation ont été portées de +/$2 \%$ à $+1-10 \%$.

En utilisant les taux de PPA établis par "le Projet de Comparaison Internationale des niveaux de vie" de 1990 et modifié par le CEPII ${ }^{4}$ de façon à tenir compte de la structure particulière des pays de l'Est, il apparaît que, malgré les pertes de compétitivitéprix enregistrées en évolution par la Pologne et la République tchèque, les niveaux de prix du PIB des trois pays de l'Est étaient encore, en 1997, sous-évalués de 54 à 60\% par

\footnotetext{
${ }^{4}$ Se reporter à la méthodologie de la "Base Chelem-PIB" du CEPII présentée dans l'annexe 2;
} 
rapport à l'Autriche ${ }^{5}$ selon la norme de PPA (tableau 1-A).

En comparant les niveaux de taux de change réel et le niveau de PIB/tête exprimé en PPA (tableau 1-B) pour les trois pays de l'Est et deux pays de niveau de vie similaire (Turquie et Mexique), la République tchèque apparaît légèrement sous-évaluée par rapport à son niveau de développement. En effet, les prix tchèques représentaient en 1997 40,2\% des niveaux des prix autrichiens alors que son PIB/tête de 8507,2 dollars international ${ }^{6}$ représentait 46,8\% du PIB/tête autrichien. La République tchèque possède ainsi le niveau de développement le plus élevé des trois pays de l'Est étudié. La Hongrie et la Pologne apparaissent légèrement surévaluées vis-à-vis de leur niveaux de développement avec des niveaux de prix qui atteignaient 46,5 et $40,3 \%$ du niveau autrichien pour des niveaux de vie inférieurs $(37,1$ et $33,6 \%$ du niveau autrichien).

En exprimant les niveaux de prix par rapport aux Etats-Unis, il apparaît que la sous-évaluation de ces monnaies est moindre, compte tenu de la dépréciation du dollar par rapport aux monnaies européenne entre 1985 et 1997. Les niveaux de prix du PIB des trois pays de l'Est atteignent en 199748 à 55\% des niveaux de prix américains.

Tableau 1-A : Niveaux de prix du PIB rapportés à celui de l'Autriche des trois pays de l'Est (1)

\begin{tabular}{|l|c|c|c|c|c|c|c|c|}
\hline & $(3)$ & 1991 & 1992 & 1993 & 1994 & 1995 & 1996 & 1997 \\
\hline USA & 1 & 83,6 & 77,5 & 81,1 & 79,0 & 69,9 & 73,6 & 83,9 \\
\hline Isrä̈l & 2 & 84,8 & 79,7 & 78,9 & 79,0 & 74,8 & $n d$ & $n d$ \\
\hline Rép. tchèque (2) & 3 & 25,6 & 27,0 & 31,3 & 33,4 & 34,9 & 39,6 & 40,2 \\
\hline Vénézuela & 4 & 28,0 & 27,0 & 27,4 & 25,9 & 28,3 & $n d$ & $n d$ \\
\hline Mexique & 5 & 40,8 & 41,2 & 45,9 & 43,5 & 26,6 & 29,9 & 39,3 \\
\hline Turquie & 6 & 36,0 & 32,4 & 34,8 & 25,3 & 26,4 & 27,4 & 30,3 \\
\hline Hongrie & 7 & 43,4 & 43,7 & 46,3 & 46,0 & 41,3 & 42,7 & 46,5 \\
\hline Pologne & 8 & 32,6 & 32,5 & 33,9 & 33,1 & 34,0 & 37,9 & 40,3 \\
\hline Brésil & 9 & 39,5 & 35,1 & 40,0 & 45,8 & 47,0 & $n d$ & $n d$ \\
\hline
\end{tabular}

(1) Le niveau du taux de change réel est défini par le rapport du PIB/tête en dollars sur le PIB/tête en PPA rapporté à celui de l'Autriche. Un indice inférieur à 100 indique une sous-évalaution des monnaies des pays de l'est par rapport à la norme de PPA.

(2) Le calcul du taux de change réel de la République tchèque avant 1993 a été effectué en recalculant un PIB réel et nominal pour ce pays (en appliquant le poids de ce pays dans le PIB de la Tchécoslovaquie en 1993).

(3) Classement des pays effectué en termes de PIB/tête PPA pour l'année 1996.

\footnotetext{
${ }^{5}$ La plupart des études prennent comme base de comparaison les Etats-Unis car les taux de change et Les taux de PPA sont généralement exprimés par rapport au dollar. Cependant, on utilise également l'Autriche comme pays de référence car ce pays fait en effet l'objet de plusieurs évaluations de taux de PPA. L'Autriche permet ainsi de passer des "taux de PPA régionaux" (ceux de l'Europe de l'Est) au "taux de PPA mondiaux" permettant des comparaisons internationales.

6 L'Institut de la statistique tchèque fait état d'un PIB/tête tchèque en dollars de PPA plus élevé. Selon cette source, il atteindrait 8888 dollars international en 1994 soit $49 \%$ du niveau de vie de l'Union européenne (Blaha [1996]).
} 
Source : Chelem PIB, calculs taux de change réels C. Baulant.

Tableau 1-B : Niveaux de PIB/tête en PPA des trois pays de l'Est (1)

\begin{tabular}{|l|c|c|c|c|c|c|c|c|}
\hline & $(3)$ & 1991 & 1992 & 1993 & 1994 & 1995 & 1996 & 1997 \\
\hline USA & 1 & 21596,3 & 21852,4 & 22296,3 & 22879,1 & 23185,9 & 23516,3 & 23819,1 \\
\hline Autriche & & 17057,9 & 17268,8 & 17226,6 & 17655,4 & 17891,8 & 18009,7 & 18191,5 \\
\hline Israël & 2 & 9129,8 & 9366,1 & 9386,0 & 9678,5 & 10018,4 & 10188,0 & $n d$ \\
\hline Rép tchèque (2) & 3 & 7787,3 & 7282,6 & 7208,3 & 7396,7 & 7756,0 & 8131,5 & 8507,2 \\
\hline Vénézuela & 4 & 7770,7 & 8055,5 & 7908,0 & 7529,1 & 7543,1 & 7317,9 & $n d$ \\
\hline Mexique & 5 & 7144,4 & 7256,0 & 7252,0 & 7425,9 & 6835,8 & 6976,6 & 7191,0 \\
\hline Turquie & 6 & 5907,2 & 6145,7 & 6521,1 & 6057,4 & 6381,8 & 6745,5 & 7012,8 \\
\hline Hongrie & 7 & 6023,3 & 6051,5 & 6084,7 & 6300,0 & 6438,3 & 6515,2 & 6754,2 \\
\hline Pologne & 8 & 4940,4 & 4925,5 & 4913,2 & 5158,5 & 5511,1 & 5806,1 & 6121,1 \\
\hline Brésil & 9 & 5172,2 & 5057,6 & 5197,9 & 5422,4 & 5579,9 & 5651,8 & $n d$ \\
\hline
\end{tabular}

(1) Le PIB/tête en PPA est défini par le PIB/tête en volume (prix de 1990) de chaque pays divisé par le taux de PPA de 1990 calculé par les organismes internationaux et revu par le CEPII (annexe 2).

(2) Le calcul du taux de change réel de la République tchèque avant 1993 a été effectué en recalculant un PIB réel et nominal pour ce pays (en appliquant le poids de ce pays dans le PIB de la Tchécoslovaquie en 1993).

(3) classement des pays effectué en termes de PIB/tête PPA pour l'année 1996.

Source : Chelem PIB, calculs et actualisation C. Baulant.

\section{graphique 1-a : taux de change réels du PIB des pays de l'Est rapportés à l'Autriche}

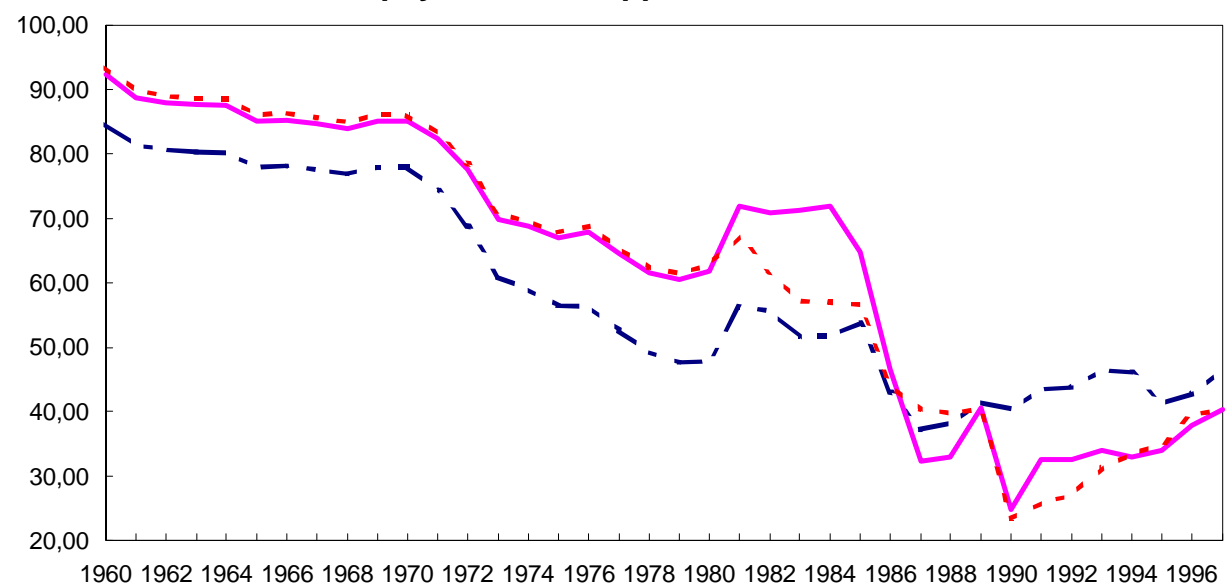
- HONGRIE
-POLOGNE
- - - Rep. Tcheque 


\section{graphique 1-b : taux de change réel du PIB des pays de l'est rapportés aux USA}

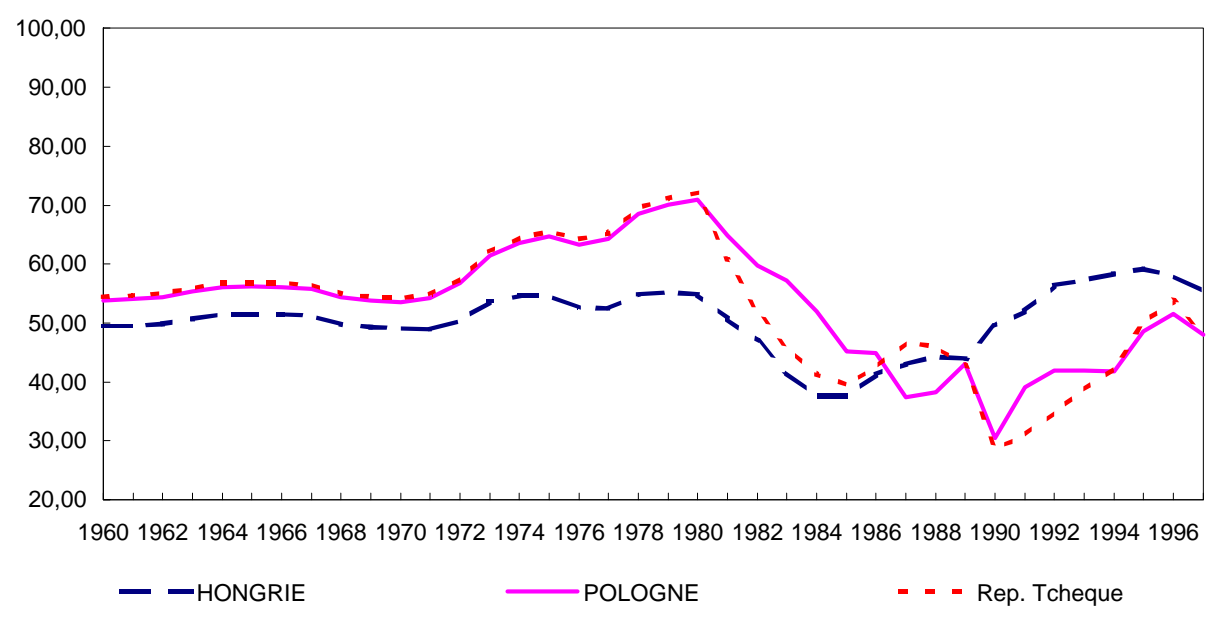

La structure des prix relatifs des pays en transition se distingue nettement de celle des prix des pays développés car l'existence d'un système de planification centralisé a entraîné des fortes distorsions des prix relatifs. Cet "effet de couvrement de coût", rend compte du fait que, dans les pays socialistes, les prix des services étaient fixes en valeur nominale pour des longues périodes. Parce que la politique sociale était directement exprimée dans les prix très bas des services, ceux-ci jouaient un rôle essentiel dans le niveau de vie des populations. Tant que la protection sociale n'est pas organisée sur la base de transferts monétaires, l'ajustement des prix des services ne peut être complet ${ }^{7}$.

Aussi, la sous-évaluation des prix du secteur exposé (par exemple le prix de la FBCF) est largement moins importante que la sous-évaluation des prix du secteur abrité (par exemple les loyers dont les prix n'ont pas encore été totalement libéralisés). Les niveaux de prix des loyers dans les trois pays de l'est atteignaient en 1997, 23 à 39\% des prix américains alors que ceux des machines étaient compris entre 100 et $149 \%$ des niveaux américains ${ }^{8}$ (tableau 1-C).

7 Se reporter à "L'ajustement des prix relatifs et convergence des prix dans les pays en transition", in World Economic Outlook, FMI, 1997, pp 120-121.

8 Deutsche Morgan Grenfell, Emerging markets, 25 novembre 1997, p 11. 
Tableau 1-C : Niveaux de prix du PIB et de ses composantes rapportés au niveau américain en 1997

\begin{tabular}{|c|c|c|c|c|}
\hline & USA & Pologne & $\begin{array}{c}\text { République } \\
\text { tchèque }\end{array}$ & Hongrie \\
\hline TCR PIB & 100 & 46,3 & 46,3 & 58,5 \\
\hline TCR conso privée & 100 & 42,0 & 40,8 & 48,31 \\
\hline a) TCR loyer énergie & $\mathbf{1 0 0}$ & $\mathbf{2 3 , 3}$ & $\mathbf{2 3 , 9}$ & $\mathbf{3 3 , 1}$ \\
\hline b) TCR transport & 100 & 63,3 & 66,6 & 74,6 \\
\hline TCR FBCF & 100 & 59,9 & 64,5 & 91,7 \\
\hline a) TCReconstruction & 100 & 46,9 & 34,7 & 63,7 \\
\hline b) TCR machines et équip. & $\mathbf{1 0 0}$ & $\mathbf{1 0 0}$ & $\mathbf{1 3 3 , 3}$ & $\mathbf{1 4 9 , 2}$ \\
\hline TCR conso publique & 100 & 42,0 & 50,0 & 80,6 \\
\hline
\end{tabular}

(1) Le niveau du taux de change réel est défini par le rapport du taux de PPA (à l'incertain) par le taux de change courant (à l'incertain). Un indice inférieur à 100 indique une sous-évaluation des monnaies des pays de l'est par rapport à la norme de PPA.

Par exemple, le taux de change réel du PIB pour la Hongrie est le rapport de 114,5965/195,96= 58,5 .

Source : Taux de PPA calculés par le projet de comparaison internationale (ICP) pour l'année 1993 et actualisé par la Deutsche Morgan Grenfell pour 1997, (Rapport du 25 novembre 1997, p 11), taux de change courant Banque de France, calculs taux de change réels C. Baulant.

L'ensemble des calculs fondés sur la PPA indique ainsi une sous-évaluation tendancielle des monnaies des pays de l'Est, même si la dégradation des balances courantes des trois pays de l'Est semble indiquer une surévaluation actuelle des taux de change courants. La norme de PPA reste en effet imparfaite pour ces pays en transition, en raison de l'effet Balassa ${ }^{9}$ et du rattrapage des prix des services.

L'analyse des niveaux de taux de change réels du PIB permet d'étudier la relation qui existe entre les niveaux de prix et leurs niveaux de développement. En revanche, les taux de change réels en évolution (bilatéraux ou effectifs) représentent des indicateurs de compétitivité-prix qui permettent d'étudier l'évolution des balances commerciales des pays d'Europe de l'Est.

\subsection{Taux de change réels en évolution}

Pour analyser la compétitivité-prix des pays, on a recours à deux définitions principales du taux de change réel. Selon la première, le taux de change réel mesure les prix relatifs des biens domestiques par rapport aux biens échangeables dans un pays donné. Selon une seconde définition, le taux de change réel mesure les prix (ou les coûts) relatifs des biens entre deux ou plusieurs pays. Compte tenu de la structure en transition des économies étudiées, nous avons retenu l'une et l'autre définitions du taux de change

${ }^{9}$ Se reporter à C. Baulant [1988]. 
réel ${ }^{10}$.

a) Taux de change réels internes : prix relatif du secteur abrité par rapport au prix du secteur exposé

L'indicateur retenu est l'évolution des prix à la consommation (représentant les prix du secteur abrité) sur le prix de production du secteur industriel (représentant les prix du secteur exposé à la concurrence internationale). Une hausse du taux de change réel, qui traduit une évolution plus rapide des prix du secteur domestique que ceux du secteur exposé à la concurrence internationale, désigne ainsi une perte de compétitivité du secteur exposé. Une hausse des prix du secteur domestique entraînera en effet une réallocation des ressources vers le secteur domestique ${ }^{11}$. La baisse relative du prix du secteur exposé aura pour conséquence de décourager l'offre de tels produits. En outre, la hausse des prix de consommation tendra à se répercuter dans les hausses de salaires ce qui se traduira, à productivité inchangée, par un accroissement des coûts unitaires de production. La compétitivité-prix s'analyse ici du côté de l'offre productive.

L'évolution du rapport des prix relatifs du secteur domestique sur les prix du secteur exposé indique pour la Pologne et la République tchèque une progression plus rapide des prix à la consommation que des prix à la production conformément à l'analyse de Balassa et à "l'effet de recouvrement des coûts". Entre 1994 et 1997, la compétitivitéprix du secteur exportateur s'est ainsi détériorée de 12,2\% en Pologne, de 8,8\% en République tchèque mais elle a augmenté de 1,3\% en Hongrie (graphique 2 et tableau 2A). D'autres calculs effectués en rapportant le prix à la consommation sur le déflateur d'investissement (représentant une seconde approximation pour évaluer le prix du secteur exposé ${ }^{12}$ ) indiquent la même tendance.

En rapportant le prix à la consommation des services sur le prix de production industriel, on obtient, en séries mensuelles, également la même évolution. Les taux de change réels internes augmentent de 19,8 et $12,4 \%$ respectivement en Pologne et en République tchèque entre janvier 1996 et février 1998. La hausse des prix relatifs hongrois est pour sa part limitée à 5,6\%.

L'appréciation tendancielle du taux de change réel interne en Pologne et en République tchèque est conforme à ce qui est attendu d'économies qui se développent par

\footnotetext{
${ }^{10}$ Se reporter aux annexes 1 et 2 pour la méthode de calcul des taux de change réels utilisés. En généralisant ce premier indicateur, on peut obtenir, pour les pays en transition, le taux de change réel des prix à la consommation. En supposant la loi du prix unique vérifiée pour les marchandises échangées, les deux indicateurs de taux de change réels peuvent traduire en effet la même évolution $\left(\mathrm{PC} / \mathrm{PT}=\mathrm{PC} / \mathrm{ePT}^{*} \cong \mathrm{PC} / \mathrm{ePC}^{*}\right)$.

11 Certains auteurs (Edward [1992]), parlent alors d'une approche "micro-économique" du taux de change réel puisqu'on analyse la réallocation des ressources productives selon la variation des prix relatifs.

12 En effet, les données issues des indices de prix de production sont souvent de mauvaise qualité et porte sur une définition large de l'industrie. Les prix de la FBCF présentent alors un avantage par rapport aux prix de production, car ils reflètent mieux les prix nationaux de l'investissement productif.
} 
l'accroissement du degré d'ouverture qui stimule l'incorporation des techniques modernes dans les secteurs exposés à la concurrence internationale. L'appréciation est entraînée par l'augmentation plus rapide de la productivité dans les secteurs exposés que dans les secteurs abrités et par la hausse plus rapide des salaires dans les secteurs abrités que dans les secteurs exposés. Ces deux mouvements peuvent s'ajouter si initialement les écarts de salaires étaient beaucoup plus grands que les écarts de productivité et si la transition réduit la disparité (Halpern et Wyplosz, 1996). Cette structure initiale de salaire donne un taux de change réel interne au début de la transition significativement sous-évalué par rapport à son niveau d'équilibre dans lequel les salaires sont conformes aux productivités sectorielles. La Hongrie n'avait pas de distorsion initiale de salaire, donc pas de taux de change réel sous-évalué pour cette raison. En outre, l'absence d'appréciation du taux de change réel interne avec l'augmentation du taux d'ouverture laisse penser que cette variable pourrait être sous-évaluée par rapport à son niveau d'équilibre.

Tableau 2-A : taux de change réels internes des trois pays d'Europe de l'est (1)

\begin{tabular}{||l|c|c|c|c|c|c|c||}
\hline & 1992 & 1993 & 1994 & 1995 & 1996 & 1997 & $1994-97$ \\
\hline TCR PC/WPI Hongrie (2) & 9,3 & 9,0 & $n d$ & $-0,1$ & 1,1 & $-2,1$ & $-1,3$ \\
\hline TCR PC/PInv Hongrie & 6,7 & 9,1 & 2,0 & 1,8 & 2,3 & 0,5 & 4,7 \\
\hline \hline TCR PC/WPI Pologne (3) & 13,9 & 3,8 & 2,3 & 2,0 & 5,8 & 4,7 & 12,2 \\
\hline TCR PC/PInv Pologne & 21,6 & 10,0 & 5,6 & 4,5 & 4,2 & $-0,2$ & 8,6 \\
\hline \hline TCR PC/WPI Rep tchèque & $n d$ & $n d$ & 4,6 & 1,4 & 3,9 & 3,3 & 8,8 \\
\hline TCR PC/PInv Rep tchèque & $n d$ & $n d$ & 0,4 & 1,1 & 0,3 & $-0,1$ & 1,3 \\
\hline \hline
\end{tabular}

(1) Le taux de change réel interne est défini par le rapport des prix à la consommation sur les WPI ou le rapport des prix à la consommation sur les prix de l'investissement privé. Un taux de croissance négatif indique une amélioration de la compétitivité du secteur exposé par rapport au secteur abrité. On a utilisé ici les WPI du FMI.

(2) De 1994 au 3ième trimestre de 1997 pour la Hongrie.

(3) De 1994 au 1er trimestre de 1997 pour la Pologne.

Taux de change réels internes des trois pays d'Europe de l'Est (évolutions mensuelles)(1)

\begin{tabular}{||l|c|c|c|c||}
\hline & $\begin{array}{c}\text { janvier 96 } \\
\text { à mai 97 }\end{array}$ & $\begin{array}{c}\text { janvier 96 à } \\
\text { novembre 97 }\end{array}$ & $\begin{array}{c}\text { janvier 96 } \\
\text { à février 98 }\end{array}$ & $\begin{array}{c}\text { janvier 95 } \\
\text { à février 98 }\end{array}$ \\
\hline TCR PC/WPI Hongrie (2) & $-2,6$ & $-4,0$ & $n d$ & $n d$ \\
\hline TCR PC/PY manuf Hongrie & $-0,2$ & 0,2 & 1,6 & 2,6 \\
\hline TCR PS/PY manuf Hongrie & 3,2 & 2,0 & 5,6 & 7,2 \\
\hline \hline TCR PC/WPI Pologne (3) & 7,5 & $n d$ & $n d$ & $n d$ \\
\hline TCR PC/PY manuf Pologne & 9 & 9,2 & 14,0 & $n d$ \\
\hline TCR PS/PY manuf Pologne & 10,2 & 10,9 & 19,8 & $n d$ \\
\hline \hline $\begin{array}{l}\text { TCR PC/WPI Rep } \\
\text { tchèque(4) }\end{array}$ & 2,9 & 7,0 & 9,3 & 11,9 \\
\hline TCR PC/PY ind rep tchèque & 2,9 & 6,9 & 9,2 & 11,9 \\
\hline TCR PS/PY ind Rep tchèque & 6,7 & 10,0 & 12,4 & 20,8 \\
\hline \hline
\end{tabular}

(1) Le taux de change réel interne est défini par le rapport des prix à la consommation sur les prix à la production ou le 
rapport des prix à la consommation des services sur les prix de de production.. Un taux de croissance négatif indique une amélioration de la compétitivité du secteur exposé par rapport au secteur abrité. On a utilisé ici les WPI du FMI et les prix de production de l'industrie de l'OCDE. Pour la Hongrie et la Pologne, il s'agit du secteur manufacturier, pour la République tchèque, il s'agit de l'ensemble de l'industrie.

(2) Le WPI s'arrête en novembre 1997 pour la Hongrie.

(3) Le WPI s'arrête en mai 1997 pour la Pologne.

(4) Le WPI de la République tchèque est très proche du prix de production de l'OCDE. Or, à la différence des deux autres pays, il s'agit du prix de production de l'ensemble de l'industrie.

Source :FMI et PIE de l'OCDE, calculs C. Baulant.

Graphique 2-A : taux de change réels internes des pays de l'Est rapport du prix à la consommation sur les prix de production (WPI)

Base janv. $1996=1$

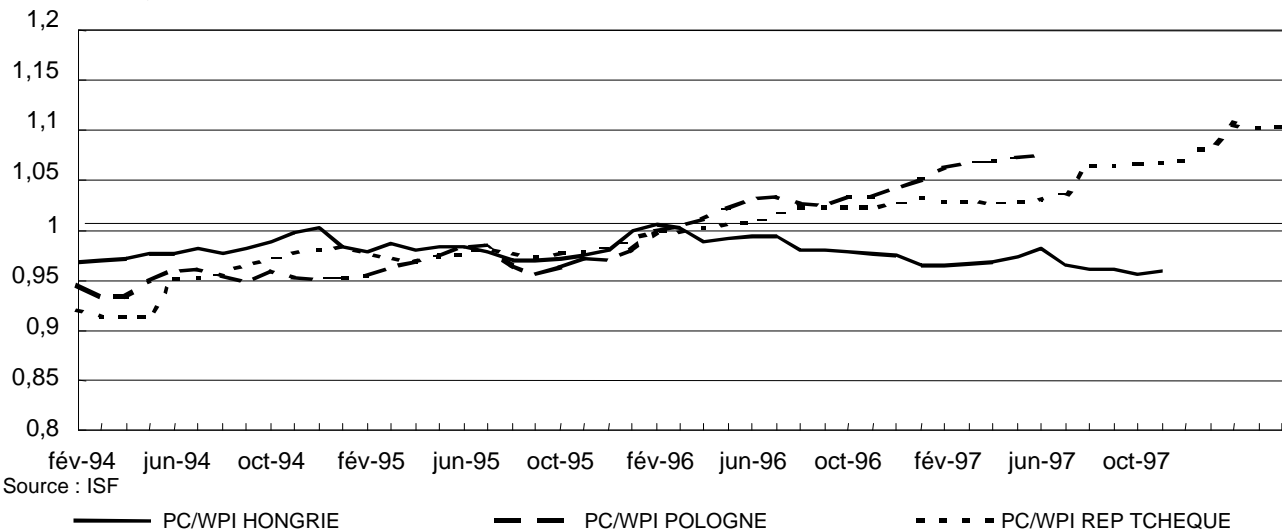


Graphique 2-B : Taux de change réels internes des pays de l'Est rapport du prix à la consommation des services sur les prix de production (PPI)

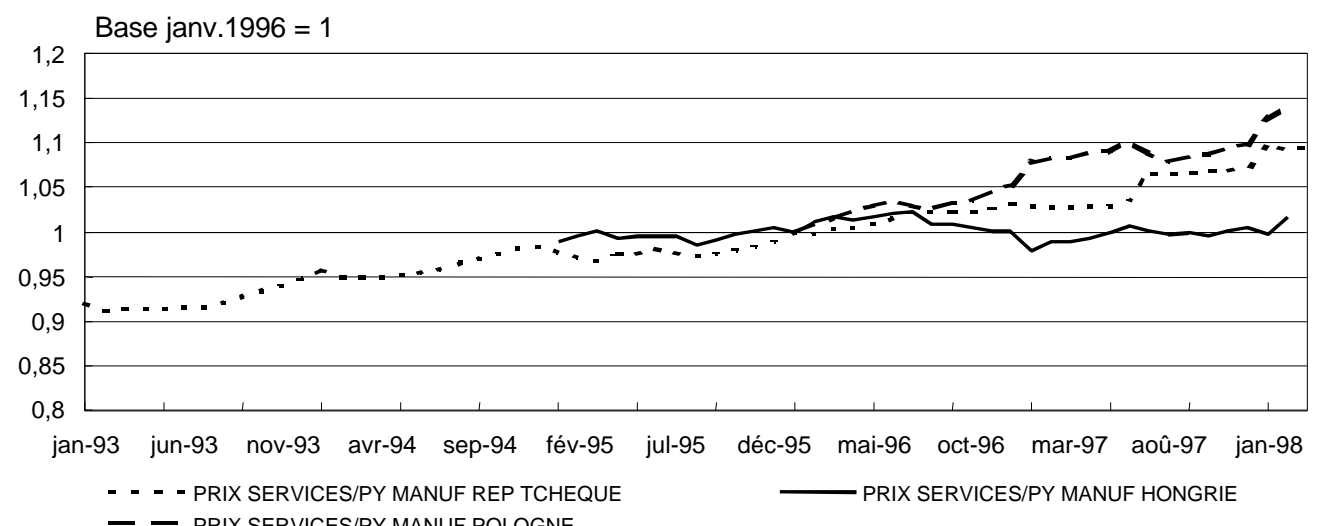

Source : PEO, déc 97

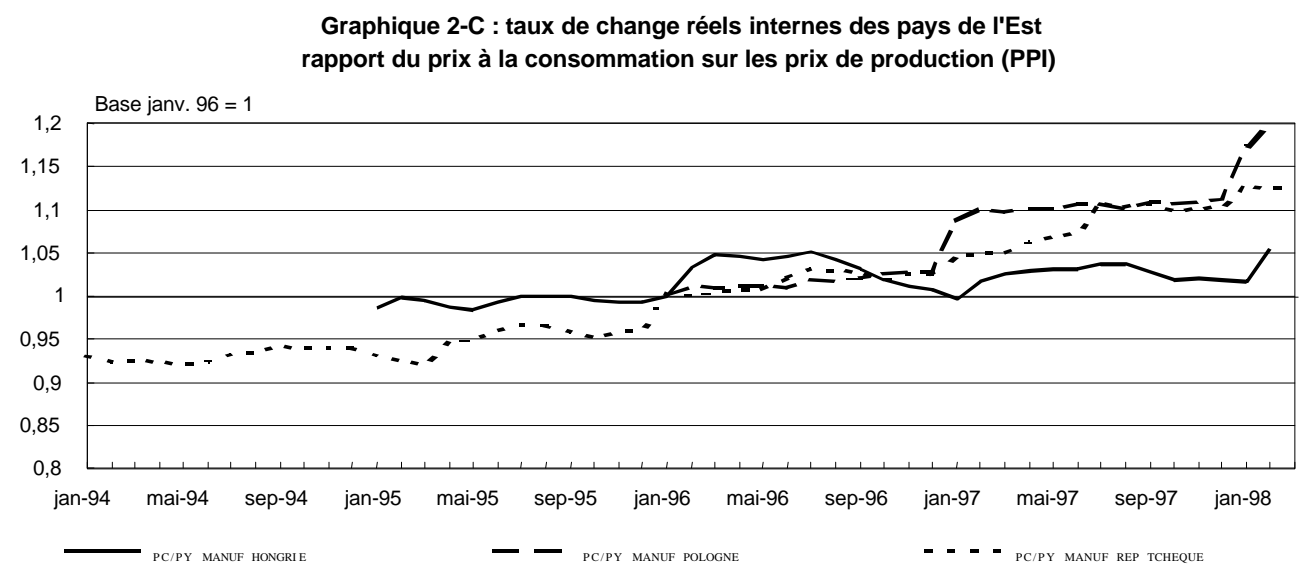

Source : PEO, déc 97

\section{b) Les taux de change réels en tant que mesure de la compétitivité}

Pour des pays de plus en plus ouverts sur l'extérieur, il est nécessaire d'analyser également la compétitivité-prix des pays sous l'angle de la demande. Dans cette optique, on s'intéresse à la capacité des pays à vendre moins chers des produits sur le marché international de façon à gagner des parts de marché en volume. 
Le calcul de taux de change bilatéraux entre les trois pays d'Europe de l'Est permet d'analyser leur position concurrentielle relative vis-à-vis de l'Union européenne. Parmi les trois pays étudiés, on note les forts gains de compétitivité-prix de la Hongrie par rapport à la Pologne et la République tchèque entre 1994 et 1997 (14,0 et 9,8\% respectivement). Dans les deux cas, ces gains ont été obtenus par la dépréciation du change alors que les prix de consommation hongrois continuent à augmenter plus rapidement que ceux des deux autres pays (Tableau 2-B). Les gains de compétitivité-prix ont été particulièrement importants en 1995 à la suite de la dévaluation du forint en mars 1995 puis s'estompent en 1996 et 1997.

La République tchèque enregistre des gains de compétitivité-prix de 4,6\% par rapport à la Pologne entre 1994 et 1997. Ces gains s'expliquent par une forte réduction du différentiel des prix à la consommation alors que la monnaie tchèque s'est appréciée par rapport à la monnaie polonaise ${ }^{13}$. En 1997, les gains de la compétitivité tchèque tendent à s'amplifier à la suite de la dépréciation de la couronne depuis mai 1997. La Hongrie et la République tchèque concurrencent ainsi de plus en plus les exportations polonaises sur les marchés européens.

13 A la différence des deux autres pays, la Pologne représente le deuxième partenaire commercial de la République tchèque avec $11 \%$ du commerce total des 10 principaux pays partenaires de la République tchèque (annexe 2). 
Tableau 2-B : Taux de change réels bilatéraux des pays d'Europe de l'Est (1)

\begin{tabular}{|l|c|c|c|c|c|c|}
\hline \multicolumn{1}{|c|}{ HONGRIE } & 1993 & 1994 & 1995 & 1996 & 1997 & $1994-97$ \\
\hline TCR Prix conso Allemagne & 6,9 & $-1,0$ & $-6,7$ & 5,1 & 9,5 & 7,4 \\
\hline TC DEM & $-8,8$ & $-14,2$ & $-25,8$ & $-14,0$ & $-5,8$ & $-39,8$ \\
\hline TCR Prix conso/USA & 2,4 & 1,1 & 4,6 & $-1,3$ & $-5,5$ & $-2,4$ \\
\hline TC Forint/dollar & $-13,8$ & $-12,8$ & $-16,0$ & $-17,9$ & $-18,2$ & $-43,5$ \\
\hline TCR Prix conso/Pologne & 2,0 & $-1,9$ & $-9,6$ & $-6,2$ & 1,4 & $-14,0$ \\
\hline TC forint/Zloty & 14,1 & 9,9 & $-10,3$ & $-8,9$ & $-0,6$ & $-18,8$ \\
\hline TCR prix conso/Rep tchèque & $n d$ & $-7,0$ & $-9,1$ & $-4,5$ & 4,0 & $-9,8$ \\
\hline TC Forint /couronne tchèque & $n d$ & $-13,8$ & $-22,5$ & $-16,1$ & $-4,8$ & $-38,1$ \\
\hline
\end{tabular}

\begin{tabular}{|l|c|c|c|c|c|c|}
\hline \multicolumn{1}{|c|}{ POLOGNE} & 1993 & 1994 & 1995 & 1996 & 1997 & $1994-97$ \\
\hline TCR prix conso/Allemagne & 4,7 & 1,0 & 3,3 & 11,9 & 8,0 & 24,9 \\
\hline TC Zloty/DEM & $-20,3$ & $-22,2$ & $-17,4$ & $-5,5$ & $-5,2$ & $-25,6$ \\
\hline TCR prix conso/USA & 0,4 & 3,1 & 15,7 & 5,0 & $-6,7$ & 13,2 \\
\hline TC Zloty/dollar & $-24,5$ & $-20,9$ & $-6,4$ & $-9,9$ & $-17,6$ & $-30,5$ \\
\hline TCR prix conso/Hongrie & $-2,0$ & 2,0 & 10,8 & 6,3 & $-1,3$ & 16,2 \\
\hline TC Zloty/Forint & $-12,5$ & $-9,1$ & 11,9 & 9,3 & 0,6 & 22,7 \\
\hline TCR prix conso/Rep tchèque & $n d$ & $-5,2$ & 0,6 & 1,7 & 2,5 & 4,9 \\
\hline TC Zloty/couronne tchèque & $n d$ & $-21,8$ & $-13,7$ & $-7,9$ & $-4,2$ & $-11,7$ \\
\hline
\end{tabular}

\begin{tabular}{|l|c|c|c|c|c|}
\hline REPUBLIQUE TCHEQUE & 1994 & 1995 & 1996 & 1997 & $1994-97$ \\
\hline TCR prix conso/Allemagne & 6,4 & 2,7 & 10,2 & 5,3 & 19,1 \\
\hline TC couronne/DEM & $-0,6$ & $-4,2$ & 2,7 & $-1,0$ & $-2,6$ \\
\hline TCR prix conso/USA & 8,8 & 15,0 & 3,4 & $-9,0$ & 8,2 \\
\hline TC couronne/dollar & 1,4 & 8,4 & $-2,2$ & $-13,9$ & $-9,5$ \\
\hline TCR prix conso/Hongrie & 7,5 & 10,1 & 4,7 & $-3,8$ & 10,8 \\
\hline TC couronne/Forint & 16,1 & 29,5 & 18,7 & 4,9 & 61,2 \\
\hline TCR prix conso/Pologne & 5,3 & $-0,6$ & $-1,6$ & $-2,5$ & $-4,6$ \\
\hline TC couronne/Zloty & 27,4 & 15,6 & 8,7 & 4,2 & 13,3 \\
\hline
\end{tabular}

(1) Le taux de change réel (TCR) est défini par le rapport des prix du pays étudié sur le prix de son partenaire (exprimé en monnaie commune). Un taux de croissance négatif indique une amélioration de la compétitivité du pays étudié.

Source : FMI (pays de l'Est) et OCDE (USA et Allemagne), calculs C. Baulant. 
Graphique 3-A : taux de change effectifs des trois pays de l'Est calculés pour les coûts salariaux unitaires

et les prix d'exportation

Base $1994=1$
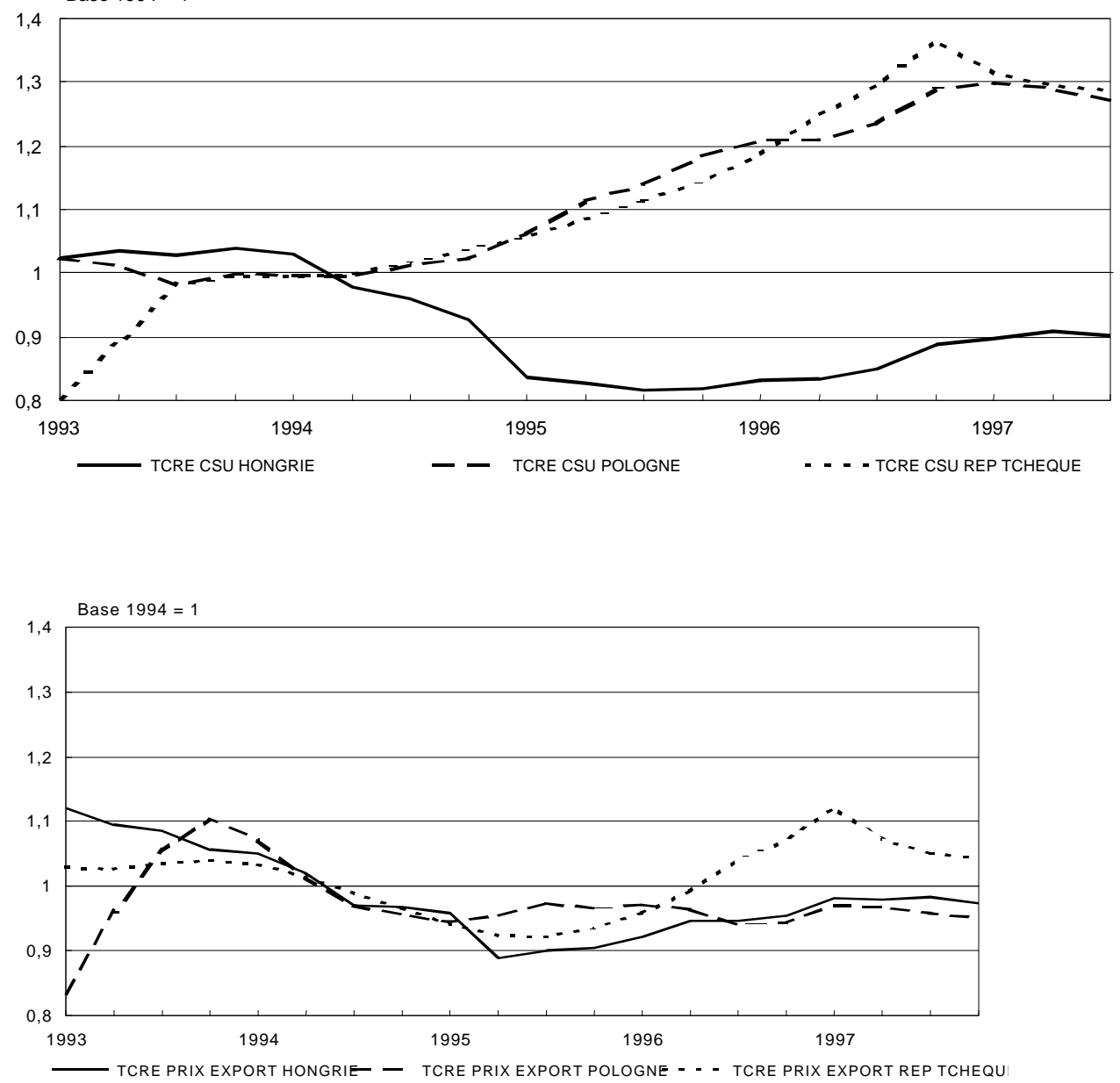


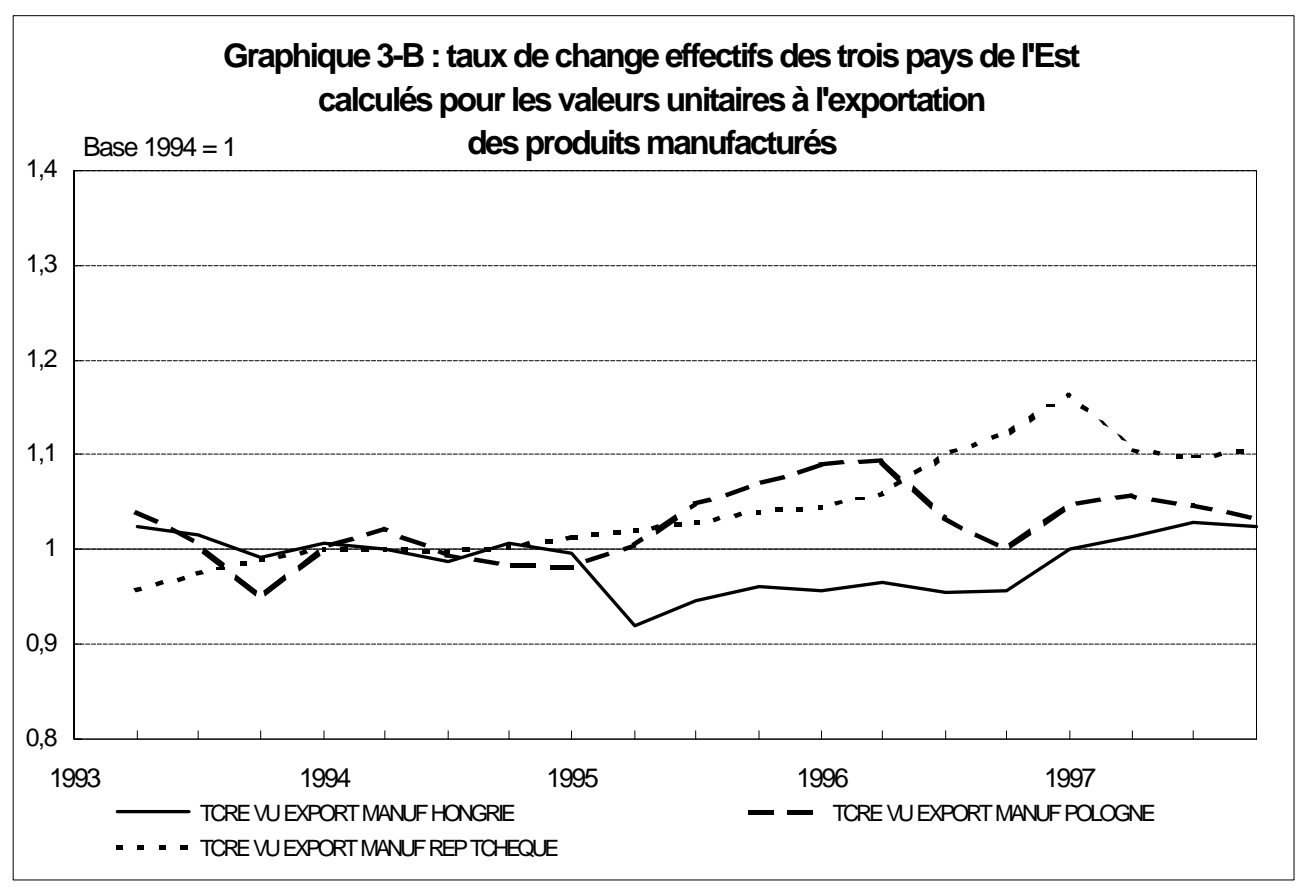

Quelque soit le mérite des taux de change bilatéraux, ce sont les taux de change effectifs qui mesurent le plus complètement l'évolution de la compétitivité des économies $^{14}$. Seules nous intéressent ici les tendances qui se dégagent depuis 1993 et les inflexions significatives. Les évolutions les plus fondamentales du point de vue de l'adaptation à la concurrence internationale se mesurent à l'aide des coûts des facteurs de production. Les données disponibles conduisent à se limiter aux coûts salariaux unitaires. Mais la concurrence se joue sur les marchés. Elle incite à calculer des taux de change réels à partir des prix à l'exportation. La comparaison des indicateurs de compétitivité-prix et de compétitivité-coût donne des indications sur la flexibilité des entreprises par la voie de la variation de leurs profits.

L'opposition tranchée des évolutions tendancielles en Hongrie vis-à-vis des deux autres pays, qui avait déjà été observée sur les taux de change réel internes, se retrouve sur l'indicateur de compétitivité-coût (graphique 3-a). On observe une dépréciation du taux de change réel ainsi mesuré d'environ 10\% de 1994 à 1997 contre une appréciation de 30\% en Pologne et de près de $40 \%$ en république tchèque (tableau 2-C). Bien qu'il y ait des raisons de penser que le taux de change réel d'équilibre doive s'apprécier sous l'effet des changements de productivité et du rattrapage des salaires rapportés plus haut, les déséquilibres de balances courantes et les pressions spéculatives font penser qu'il y a eu un surajustement.

14 Les 10 premiers pays partenaires des trois pays de l'Est sont l'Allemagne, l'Autriche, l'Italie, la France, le Royaume-Uni, les Pays-Bas, la Belgique, les Etats-Unis, la Hongrie et la Pologne. 
La politique de modération de la demande en Pologne et la modification du régime de change en république tchèque (voir encadré) reflètent la correction du surajustement. La comparaison de la compétitivité-coût et de la compétitivité-prix à l'exportation confirme ce diagnostic. En effet, si l'évolution du taux de change réel est d'équilibre, les deux indicateurs doivent évoluer de concert, parce que les prix à l'exportation incorporent un taux de marge stable sur les coûts salariaux unitaires. Au contraire, un taux de change réel sur les prix à l'exportation qui s'apprécie systématiquement moins qu'un taux de change réel selon les coûts salariaux désigne un écrasement des marges à l'exportation, symptôme d'une surévaluation réelle. A l'inverse, un taux de change réel selon les prix d'exportation qui se déprécie moins qu'un taux de change réel selon les coûts salariaux exprime une augmentation des marges à l'exportation, symptôme d'une sous-évaluation réelle.

La comparaison des deux éléments du graphique 3-a confirme la différenciation tranchée entre la Hongrie d'un côté, les deux autres pays de l'autre. La progression des coûts salariaux unitaires étant systématiquement inférieure à celle des prix d'exportation en Hongrie, les marges apparentes augmentent. C'est l'inverse qui se passe en République tchèque et surtout en Pologne. Cependant, des indicateurs complémentaires tendent à montrer que la Pologne se place entre la Hongrie et la République tchèque. 
Tableau 2-C : Taux de change réels effectifs des trois pays Europe de l'est par rapport aux 10 principaux pays partenaires $(1)$

\begin{tabular}{|l|c|c|c|c|c|c|}
\hline HONGRIE & 1993 & 1994 & 1995 & 1996 & 1997 & $\begin{array}{l}1994 \text { à } \\
1997\end{array}$ \\
\hline TCE nominal & $-6,4$ & $-13,1$ & $-23,2$ & $-15,4$ & $-7,4$ & $-39,8$ \\
\hline TCRE csu & $\mathbf{7 , 8}$ & $\mathbf{- 2 , 5}$ & $\mathbf{- 1 5 , 1}$ & $\mathbf{- 2 , 1}$ & $\mathbf{7 , 8}$ & $\mathbf{- 1 0 , 3}$ \\
\hline TCRE val unit export manuf & $n d$ & 11,7 & $-4,4$ & 0,3 & 6,1 & 1,7 \\
\hline TCRE val unit export total & $n d$ & 13,2 & $-2,3$ & 4,0 & 5,6 & 7,4 \\
\hline TCRE prix export total & $\mathbf{n d}$ & $\mathbf{- 8 , 1}$ & $\mathbf{- 8 , 8}$ & $\mathbf{3 , 2}$ & $\mathbf{3 , 9}$ & $\mathbf{- 2 , 3}$ \\
\hline TCRE prix consommation & 9,5 & $-0,4$ & $-4,7$ & 2,3 & 7,3 & 4,8 \\
\hline
\end{tabular}

\begin{tabular}{|l|c|c|c|c|c|c|}
\hline POLOGNE & 1993 & 1994 & 1995 & 1996 & 1997 & $\begin{array}{l}1994 \text { à } \\
1997\end{array}$ \\
\hline TCE nominal & $-19,0$ & $-21,5$ & $-14,4$ & $-7,0$ & $-7,1$ & $-26,0$ \\
\hline TCRE csu & $\mathbf{- 3 , 9}$ & $\mathbf{- 1 , 1}$ & $\mathbf{8 , 5}$ & $\mathbf{1 1 , 5}$ & $\mathbf{6 , 5}$ & $\mathbf{2 8 , 7}$ \\
\hline TCRE val unit export manuf & $n d$ & 12,6 & 2,6 & 2,8 & $-0,8$ & 4,6 \\
\hline TCRE val unitexport total & $n d$ & 12,5 & 1,2 & 2,3 & $-0,8$ & 2,7 \\
\hline TCRE prix export total & $\mathbf{n d}$ & $\mathbf{1 , 5}$ & $\mathbf{- 4 , 3}$ & $\mathbf{- 0 , 5}$ & $\mathbf{0 , 7}$ & $\mathbf{- 3 , 9}$ \\
\hline TCRE prix consommation & 7,0 & 1,6 & 6,1 & 9,2 & 5,5 & 22,0 \\
\hline
\end{tabular}

\begin{tabular}{|l|c|c|c|c|c|}
\hline REPUBLIQUE TCHEQUE & 1994 & 1995 & 1996 & 1997 & $\begin{array}{l}1994 \text { à } \\
1997\end{array}$ \\
\hline TCE nominal & 2,8 & 0,2 & 2,3 & $-1,7$ & 0,9 \\
\hline TCRE csu & $\mathbf{1 7 , 4}$ & $\mathbf{7 , 2}$ & $\mathbf{1 3 , 5}$ & $\mathbf{8 , 0}$ & $\mathbf{3 1 , 5}$ \\
\hline TCRE val unit export manuf & 16,2 & 2,6 & 5,4 & 3,4 & 11,8 \\
\hline TCRE val unit export total & 15,3 & 0,6 & 5,5 & 3,8 & 10,1 \\
\hline TCRE prix export total & $\mathbf{- 3 , 1}$ & $\mathbf{- 7 , 0}$ & $\mathbf{9 , 2}$ & $\mathbf{5 , 5}$ & $\mathbf{7 , 1}$ \\
\hline TCRE prix consommation & 6,7 & 4,1 & 7,1 & 2,9 & 14,7 \\
\hline
\end{tabular}

(1) Le taux de change réel effectif (TCRE) est défini par le rapport des prix du pays considéré sur le prix moyen de ses pays partenaires (exprimé en monnaie commune). Un taux de croissance négatif indique une amélioration de la compétitivité du pays étudié.

Source : FMI et PEO décembre 1997 (pays de l'Est) et OCDE (pays développés), calculs taux de change réels $C$. Baulant. 
Les analyses empiriques de la compétitivité-prix montrent l'importance de la formation des coûts et des prix dans l'adaptation différenciée des trois pays à la contrainte extérieure. Ces relations sont cruciales pour étudier l'incidence des modifications du taux de change sur les équilibres internes et externes. Elles vont être étudiées dans la partie suivante.

\section{LE COMMERCE EXTÉRIEUR}

Les trois pays étudiés sont de plus en plus ouverts sur le commerce international (tableau 3).

Tableau 3 : Degré d'ouverture des échanges commerciaux des pays d'Europe centrale et orientale vis à vis de 17 pays de l'OCDE

(données annuelles en \%)

\begin{tabular}{|l|l|l|l|l|l|l|l|l|}
\hline & 1989 & 1990 & 1991 & 1992 & 1993 & 1994 & 1995 & 1996 \\
\hline Pays & 13,2 & 13,8 & 16,2 & 16,7 & 16,3 & 18,8 & 22,8 & 24,8 \\
\hline Pays & 6,8 & 13,0 & 13,6 & 13,8 & 14,2 & 15,3 & 16,1 & 15,9 \\
\hline Pologne & - & - & - & - & 23,0 & 26,3 & 28,6 & 28,7 \\
\hline
\end{tabular}

Source : Séries d'exportations et d'importations de biens extraites de l'OCDE (séries "A"), calculs Banque de France-DGSE-SAMI.

L'ouverture est mesurée par la demi-somme des exportations et des importations rapportée au PIB. Lorsque les échanges extérieurs d'un pays font une part plus grande de la production, la variation du taux de change a un effet direct accru sur la production, si du moins les élasticités-prix du commerce extérieur restent constantes. Cependant l'ouverture rend aussi les prix intérieurs plus sensibles aux variations des prix internationaux exprimés en monnaie nationale. L'impact du degré d'ouverture sur la production et la balance commerciale est donc complexe. D'un côté l'ouverture plus grande renforce l'effet de croissance, d'un autre côté la perte d'autonomie des prix intérieurs à l'influence extérieure détériore les gains de compétitivité. Une modélisation simple est utile pour étudier l'effet des paramètres structurels qui interagissent dans ces relations. Elle pourra guider les estimations empiriques et aidera à caractériser les trois pays vis à vis de la contrainte extérieure.

\subsection{Incidence du taux d'ouverture}

On s'intéresse à l'effet d'une variation du taux de change sur les variations de la production et de la balance commerciale pour différents niveaux du taux d'ouverture. Pour obtenir des équations de base linéaires, on considère que les variables sont les variations des logarithmes des grandeurs économiques sous-jacentes.

Ecrivons d'abord le modèle en supposant que la variation du niveau des prix intérieurs est exogène. 
(1) $X=\varepsilon_{x}\left(e-p_{x}\right)$

(2) $M=\mu Y+\varepsilon_{m}\left(p-p_{m}\right)$

(3) $Y=D+a(X-M)$

(4) $R=Y+a\left(p_{x}-p_{m}\right)$

(5) $D=\lambda R$

(6) $\mathrm{p}_{\mathrm{X}}=\alpha_{\mathrm{X}}\left(\mathrm{e}+\mathrm{p}^{*}\right)+\left(1-\alpha_{\mathrm{X}}\right) \mathrm{p}$

(7) $\mathrm{p}_{\mathrm{m}}=\alpha_{\mathrm{m}}\left(\mathrm{e}+\mathrm{p}^{*}\right)+\left(1-\alpha_{\mathrm{m}}\right) \mathrm{p}$

(8) $q=p-e$

(1) et (2) sont les fonctions du commerce extérieur dépendant de la compétitivité à l'exportation et à l'importation, ainsi que de la production pour l'importation.

(3) exprime l'équilibre du marché intérieur en fonction du taux d'ouverture a.

(4) définit la variation du revenu réel. Il dépend de l'enrichissement sur l'extérieur ou du prélèvement par l'extérieur selon le sens de variation des termes de l'échange. La contribution de l'extérieur à la variation du revenu global augmente avec le taux d'ouverture.

(5) énonce que la variation de l'absorption dépend de celle du revenu réel et de la propension marginale à dépenser.

(6) et (7) décrivent la formation des prix du commerce extérieur selon l'arbitrage des entreprises entre la répercussion de leurs coûts et la pression de leurs concurrents.

(8) définit la variation du taux de change réel.

En résolvant les équations (1) à (8) et en supposant constant les prix étrangers, qui est exogène, on établit la relation entre la variation de la production et celle du taux de change réel pour chaque niveau du taux d'ouverture.

(9) $Y=-\frac{1}{\mu+\frac{1-\lambda}{a}}\left[\varepsilon_{x}\left(1-\alpha_{x}\right)+\varepsilon_{m} \alpha_{m}-\lambda\left(\alpha_{m}-\alpha_{x}\right)\right] q$

L'incidence sur la balance commerciale peut être mesurée par le ratio :

$\frac{\text { Variation de la balance }}{\text { Niveau du PIB }}=Z$

Au voisinage de l'équilibre de la balance :

$\mathrm{Z}_{1}=a\left[\left(X+p_{x}\right)-\left(M+p_{m}\right)\right]$ 
$\mathrm{Au}$ voisinage d'une situation quelconque de la balance définie par un taux de couverture $b=\frac{\text { valeur des exportations }}{\text { valeur des importations }}$ :

$$
\mathrm{Z}_{2}=a\left[b\left(X+p_{x}\right)-\left(M+p_{m}\right)\right]
$$

En posant :

$\eta=\varepsilon_{x}\left(1-\alpha_{x}\right)+\alpha_{x}-\left(1-\varepsilon_{m}\right) \alpha_{m}$

qui est la différence des élasticités en valeur à l'exportation et à l'importation, on trouve :

(10) $\mathrm{Z}_{1}=-a\left[\eta-\frac{\mu}{\mu+\frac{1-\lambda}{a}}\left(\eta+(1-\lambda)\left(\alpha_{m}-\alpha_{x}\right)\right)\right] q$

L'équation (9) montre que l'élasticité de Y par rapport à q est fonction croissante de a : plus le taux d'ouverture est élevé, plus la dépréciation réelle du taux de change augmente le taux de croissance, bien que l'efficacité marginale de l'ouverture $\frac{d(Y / q)}{d a}$ soit décroissante.

L'équation (10), au contraire, montre que $\frac{\mathrm{Z}_{1}}{q}$ est une fonction de a qui admet un maximum. Pour des taux d'ouverture faibles, la balance commerciale rapportée au PIB s'améliore d'autant plus que ce taux d'ouverture augmente. Au delà du degré d'ouverture à effet maximal, la dépréciation réelle a une influence favorable de moins en moins forte sur la balance commerciale lorsque le taux d'ouverture s'accroît. La balance peut même se détériorer pour des taux d'ouverture élevés. La raison se trouve dans l'incidence du taux d'ouverture sur la croissance conformément à (9). Plus la croissance est élevée, plus les importations sont fortes, surtout dans des économies en transition qui importent une grande partie des biens intermédiaires industriels et l'essentiel des biens d'équipement. Si cet effet l'emporte sur la compétitivité, la balance commerciale se détériore avec la dévaluation.

Lorsque le taux de couverture $\mathrm{b}$ est différent de $1, \mathrm{Z}_{2}$ en dépend. En outre, $\mathrm{Z}_{2}$ dépend directement de la variation du niveau des prix intérieurs $p$, hormis l'influence de $p$ à travers q, selon (11) :

$$
\begin{aligned}
& \text { (11) } \mathrm{Z}_{2}=-a\left[b \alpha_{x}+b \varepsilon_{x}\left(1-\alpha_{x}\right)-\left(1-\varepsilon_{m}\right) \alpha_{m}\right] q-a(1-b) p \\
& +\frac{a \mu}{\mu+\frac{1-\lambda}{a}}\left[\eta+(1-\lambda)\left(\alpha_{m}-\alpha_{x}\right)\right] q
\end{aligned}
$$


Les courbes $\frac{\mathrm{Z}_{2}}{q}$ en fonction de a ont la même forme que $\frac{\mathrm{Z}_{1}}{q}$. Cependant si les pays ont des balances commerciales structurellement déficitaires $(b<1)$, l'amélioration de la balance avec la dévaluation réelle est amortie pour les petites valeurs de a, le degré d'ouverture optimal est abaissé et la dégradation de la balance pour les grandes valeurs de a est plus prononcée.

En outre, les équations (9), (10), (11) sont exprimées par rapport au taux de change réel. Mais cette variable ne peut pas être considérée comme exogène. Car les prix intérieurs réagissent à la variation du taux de change nominal.

Complétons le modèle par une détermination très simple des prix en incorporant une indexation croisée du salaire (w), du prix de la demande finale $\left(p_{u}\right)$ et du prix intérieur (p). $\varepsilon$ est une tendance exogène de rattrapage des salaires dont le niveau initial est très bas par rapport à celui des économies de marché.

(12) $w=\beta p_{u}+\varepsilon$

(13) $p=\gamma w$

(14) $p_{u}=a p_{m}+(1-a) p$

Ces trois équations jointes à (7) déterminent $\mathrm{p}$ en fonction de $\mathrm{e}$ :

(15) $p=\frac{a \alpha_{m} \beta \gamma e}{1-\left(1-a \alpha_{m}\right) \beta \gamma}+\frac{\gamma \varepsilon}{1-\left(1-a \alpha_{m}\right) \beta \gamma}$

L'élasticité de la variation du prix intérieur à la variation du taux de change nominal est fonction croissante de l'indexation croisée $\beta \gamma$. Lorsque $\beta \gamma=1$, on trouve $p=e+\frac{\gamma \varepsilon}{a \alpha_{m}}$. Ce résultat bien connu rappelle que l'indexation parfaite des prix intérieurs sur la variation du change empêche toute modification des prix relatifs provenant d'une variation du taux de change nominal. La variation du taux de change nominal n'a alors aucun effet réel.

Lorsque $\beta \gamma \leq 1$, le taux de change réel s'exprime en fonction du taux de change nominal :

(16) $q=-\frac{(1-\beta \gamma) e}{1-\left(1-a \alpha_{m}\right) \beta \gamma}+\frac{\gamma \varepsilon}{1-\left(1-a \alpha_{m}\right) \beta \gamma}$

Enfin $\mathrm{p}$ et q sont des fonctions croissantes de a. Lorsque le taux d'ouverture est plus élevé, les prix et revenus intérieurs dépendent plus des prix étrangers et du taux de change. L'augmentation de $\mathrm{p}$ avec une dévaluation nominale amenuise la baisse du taux de change réel consécutive à cette dévaluation. L'incidence réelle sur la production et la balance commerciale est réduite également. Cette incidence est obtenue en remplaçant q 
par son expression (16) dans (9) et (10), en remplaçant q par (16) et p par (15) dans (11).

Pour comparer les effets de la variation du taux de change dans les trois pays sur l'équilibre interne et sur l'équilibre externe, il faut estimer les paramètres structurels du modèle.

\subsection{Prix et volume du commerce extérieur}

\section{a) Prix du commerce extérieur des produits manufacturés dans les trois pays}

La formation de prix du commerce extérieur est modélisée au moyen de deux variables, les prix étrangers exprimés en monnaies nationales et les coûts salariaux unitaires. Ces variables représentent l'arbitrage que les entreprises des secteurs exportateur et importateur sont susceptibles d'effectuer entre l'amélioration de la compétitivité-prix et les gains de profitabilité. Pour analyser la signification des coefficients et effectuer un traitement homogène des trois économies, nous avons privilégié une équation de formation des prix où la somme des coefficients des prix étrangers et des coûts salariaux unitaires est contrainte à l'unité.

Les trois pays sont "price taker" à l'importation comme à l'exportation. Ce résultat s'explique par la transition vers l'économie de marché qui s'accompagne d'une ouverture croissante aux produits des pays développés. Entre 1993 et 1996, le degré d'ouverture des échanges commerciaux de la République tchèque vis-à-vis de 17 pays de l'OCDE est passé de 23 à 28,7\%, celui de la Hongrie est passé de 16,3 à 24,8\% et celui de la Pologne de 14,2 à $15,9 \%(\underline{\text { tableau } 3})^{15}$.

\section{Prix d'exportation}

Les trois pays sont plutôt "price taker" à l'exportation (tableau 4). Ce résultat rend compte de l'ouverture croissante de ces économies, qui rend les prix d'exportation plus sensibles à la concurrence étrangère et donc plus dépendants des prix étrangers exprimés en monnaies nationales. Cette indexation amenuise ainsi les gains de compétitivité-prix anticipés à la suite de la dévaluation.

Dans nos estimations, la Hongrie et la Pologne sont fortement "price taker" $(0,77$ et 0,75 respectivement). Une dévaluation de $10 \%$ du taux de change nominal pour ces deux premiers pays se traduit par une hausse du prix d'exportation de 7,7 et 7,5\% respectivement. Les gains de compétitivité-prix seraient alors limités à à 2,3 et 2,5\% respectivement. Pour ces deux pays, la dévaluation de la monnaie nationale ne se traduit pas par une baisse marquée des prix d'exportation exprimés en monnaie étrangère, mais par une reconstitution des marges des exportateurs sous forme d'une hausse des prix en

\footnotetext{
15 L'ouverture de la Pologne au commerce des pays de l'OCDE s'est effectuée plus tôt en passant de 6,8 à $13 \%$ entre 1989 et 1990, celle de la Hongrie a également progressé au début des années 1990 (en passant de 13,8 en 1990 à 16,2\% en 1991).
} 
monnaie nationale ${ }^{16}$. La République tchèque est moins "price taker" avec un coefficient de 0,63 . La dévaluation de $10 \%$ du change nominal aura pour effet d'accroître plus fortement la compétitivité-prix $(3,7 \%)$.

Le "pass-through", qui mesure le degré de répercussion des variations de change, sur les prix d'exportation exprimés en devises, est donc plus faible en Hongrie et en Pologne qu'en République tchèque.

\section{Prix d'importation}

Conformément à la formation des prix d'importation, les trois pays sont "price taker" à l'importation. La hiérarchie des trois pays est ici inversée. La République tchèque est très dépendante de la formation des prix d'exportation étrangers $(0,83)$ alors que la Hongrie l'est sensiblement moins $(0,53)$. La Pologne se situe dans une situation intermédiaire, mais proche de la République tchèque, avec un coefficient de dépendance de 0,78 .

Le "pass-through" à l'importation est donc plus faible en République tchèque et en Pologne qu'en Hongrie. A la suite d'une dévaluation de $10 \%$ de la monnaie des pays de l'Est, les prix d'importation tchèques et polonais en monnaies nationales augmentent respectivement de 8,3 et $7,8 \%$. En devises, les prix d'importation tchèques et polonais diminuent alors faiblement ( 1,7 et $2,2 \%$ respectivement) tandis que les prix d'importation hongrois exprimés en devises baissent de 4,7\%. La variation du taux de change est ainsi moins répercutée dans le prix d'importation en Hongrie qu'en République tchèque alors que, pour le prix d'exportation, la répercussion était similaire.

La République tchèque et la Pologne seraient, conformément à la théorie économique, plus "price taker" à l'importation et moins "price taker" à l'exportation. Les producteurs nationaux contrôlent mieux la formation de leurs prix à l'exportation puisque les produits exportés, témoins de leur bonne compétitivité, leur permettent de fixer leur prix sur la base de leurs coûts de production nationaux. Au contraire, les producteurs nationaux concurrents des importations produisent insuffisamment ou à des coûts excessifs, les prix d'importation de ces produits sont alors déterminés par les prix d'exportation des pays étrangers. De façon paradoxale, la Hongrie serait dans nos estimations plus "price taker" à l'exportation qu'à l'importation $(0,77$ contre 0,53$)$. A la suite de la dévaluation de $10 \%$, la Hongrie obtiendrait des gains de termes de l'échange de $2,4 \%$ tandis que la République tchèque, et dans une moindre mesure la Pologne, obtiendraient des pertes $(-1,9$ et $-0,3 \%$ respectivement).

Dans tous les cas, la compétitivité-prix à l'exportation comme à l'importation de la République tchèque s'améliore plus fortement à la suite de la dévaluation de sa monnaie que celles des deux autres pays. Aussi, le changement de politique de change, qui est intervenu depuis mai 1997 (flottement géré de la couronne par rapport au mark) devrait se

16 Cette évolution était également soulignée dans le rapport de 1995 de l'OCDE portant sur la Hongrie (p 91). 
traduire par des gains de compétitivité-prix. 
Tableau 4 : Estimations des prix des exportations et des importations des produits manufacturés entre le deuxième trimestre de 1993 et le troisième trimestre de 1997

(la somme des coefficients est contrainte à l'unité)

$$
\begin{gathered}
\log (P X)=\operatorname{ax} \log \left(P^{*} . e\right)+\quad(1-\alpha x) \log (c s u)+C x \\
\log (P M)=\alpha m \log \left(P^{*} . e\right)+\quad(1-\alpha m) \log (c s u)+C m
\end{gathered}
$$

\begin{tabular}{|l|c|c|c|c|c|c|}
\hline & \multicolumn{3}{|c|}{ prix d'exportation } & \multicolumn{3}{c|}{ prix d'importation } \\
\hline & Hongrie & Pologne & $\begin{array}{c}\text { Rép. } \\
\text { tchèque }\end{array}$ & Hongrie & Pologne & $\begin{array}{c}\text { Rép. } \\
\text { tchèque }\end{array}$ \\
\hline csu total & 0,234 & 0,255 & 0,366 & 0,472 & 0,222 & 0,174 \\
\hline $\begin{array}{l}\text { prix étrangers en } \boldsymbol{M} \\
\text { nat. }\end{array}$ & $\begin{array}{c}\mathbf{0 , 7 6 6} \\
(\mathbf{1 4 , 3 )}\end{array}$ & $\begin{array}{c}\mathbf{0 , 7 4 5} \\
(\mathbf{1 0 , 5 4})\end{array}$ & $\begin{array}{c}\mathbf{0 , 6 3 4} \\
\mathbf{( 2 9 , 4 3 )}\end{array}$ & $\begin{array}{c}\mathbf{0 , 5 2 8} \\
(\mathbf{1 4 , 9 7 )}\end{array}$ & $\begin{array}{c}\mathbf{0 , 7 7 8} \\
(\mathbf{1 0 , 6 8})\end{array}$ & $\begin{array}{c}\mathbf{0 , 8 2 6} \\
(\mathbf{3 5 , 3 6})\end{array}$ \\
\hline somme des élasticités & 1 & 1 & 1 & 1 & 1 & 1 \\
\hline constante & 0,0069 & $-0,0002$ & 0,0056 & 0,0112 & 0,00051 & 0,0079 \\
$(1,02)$ & $(-0,02)$ & $(1,50)$ & $(2,43)$ & $(0,05)$ & $(1,99)$ \\
\hline SER & 0,0209 & 0,02949 & 0,01311 & 0,0141 & 0,02938 & 0,01404 \\
\hline$R^{2}$ corrigé & 0,9228 & 0,8662 & 0,9807 & 0,9292 & 0,8693 & 0,9865 \\
\hline DW & 1,004 & 1,0612 & 1,150 & 0,9939 & 1,0185 & 1,1785 \\
\hline
\end{tabular}

Source : FMI, PEO décembre 1997, séries A de l'OCDE, Régressions économétriques de C. Baulant.

\section{b) Formation des salaires}

Depuis la libéralisation de la plupart des prix en 1989-90, l'inflation suit dans les trois pays une tendance régulièrement décroissante. En 1997, l'indice des prix à la consommation de la Pologne n'a augmenté que de 15,9\% en moyenne annuelle, taux le plus bas depuis le début de la transition. La surchauffe qu'a connue la Pologne n'a pas provoqué une reprise de l'inflation, en raison de la hausse du taux de change réel et de la baisse des prix d'importation de ce pays qui ont entraîné de la désinflation importée. La surchauffe de l'économie s'est traduite par des déséquilibres extérieurs grandissants.

La désinflation a été régulière dans l'ensemble des trois pays, en dehors des déviations de courte durée imputables aux facteurs saisonniers, aux chocs du côté de l'offre ou des mesures fiscales. L'inflation a été plus contenue en République tchèque $(8,5 \%$ en 1997), mais elle est plus forte en Hongrie $(18,3 \%)^{17}$.

Les forts taux d'inflation de la période de la transition ont pourtant conduit à un

${ }^{17}$ Le taux d'inflation de la Pologne est, depuis 1995, inférieur à celui de la Hongrie. 
usage généralisé de l'indexation. Selon nos estimations, l'indexation serait égale à 0,86 en Hongrie et 0,73 en Pologne (tableau 5).

En Pologne, quatre mécanismes différents ont été mis en oeuvre pour amortir l'influence inflationniste d'une boucle prix-salaire en limitant les hausses de salaires ${ }^{18}$. Ces mécanismes visent à autoriser un lien entre les résultats des entreprises et les augmentations des salaires.

Une forme modifiée de l'impôt sur les augmentations excessives de salaires (le "popiwek") est restée en vigueur pendant le premier trimestre de 1994.

- Un nouveau système de convention collective est apparu en janvier 1995. La politique des revenus fondée sur la fiscalité a été remplacée par une approche fondée sur un dialogue entre les partenaires sociaux. Chaque année, une Commission nationale tripartite fixe des plafonds aux augmentations de salaires imputables sur les coûts, à partir des prévisions du PIB, de l'inflation et des augmentations maximales de salaires accordées par le secteur public.

Malgré la progression plus rapide que prévu des prix à la consommation en 1995, les hausses de salaires maximales ont été fixées à un niveau légèrement supérieur. Dans la pratique, la nouvelle politique des salaires s'apparente à une politique d'indexation de fait, mais les autorités ont la possibilité de s'opposer à une indexation automatique et intégrale.

Les pensions étaient indexées sur les salaires de 1991 à 95. L'ajustement était automatiquement déclenché en cas de hausse de $10 \%$ du salaire trimestriel moyen depuis le dernier ajustement. Etant donné le poids grandissant des pensions, le lien entre les pensions et les salaires a été supprimé à compter de 1996.

En République tchèque, une indexation unitaire des salaires sur les prix de consommation a été retenue. Elle rend compte de la forte dérive des salaires tchèques. La hausse des salaires réels et des coûts salariaux unitaires en République tchèque s'explique par différents facteurs. D'abord, pendant des années, les niveaux de salaires tchèques ont été faibles, ce qui a entraîné une délocalisation des entreprises allemandes en République tchèque. La sous-traitance de produits de base et produits semi-finis a permis d'adapter les industries manufacturières tchèques aux critères occidentaux. Cela ne peut cependant, en aucun cas constituer une assise solide pour une compétitivité durable. Ensuite, le taux de chômage de la République tchèque est le plus faible des trois économies étudiées $(3,1 \%$ en 1995 contre 13,3 et 10,3\% respectivement pour la Pologne et la Hongrie). En outre, il s'agit d'un chômage "frictionnel", touchant surtout les jeunes et les travailleurs sans qualification. L'économie tchèque a été également la première économie de l'Est à restructurer sa production manufacturière vers des produits à plus forte valeur ajoutée. La hausse de la qualité des produits a entraîné des revendications salariales alors que la hausse des prix était relativement contenue. Enfin, le marché du travail tchèque est

${ }^{18}$ Etudes économiques de l'OCDE : 1996-97 : Pologne, p 33-34. 
caractérisé de plus en plus par des pénuries de main d'oeuvre qualifiée. Ces pénuries s'expliquent par une désorganisation du système d'enseignement professionnel public et privé (modifié en 1991) ainsi qu'une inadaptation de l'offre de travail de la part des entreprises (Blaha [1996]).

La République tchèque a ainsi connu de fortes hausses des salaires réels durant la période étudiée. La baisse de l'indexation des salaires en fin de période pourrait cependant expliquer la réduction du déficit commercial observé depuis mai 1997. Selon les dernières prévisions de l'OCDE, les salaires devraient stagner en 1998 puis baisser en 1999 (OCDE [1998]).

L'indexation des salaires pose le problème de l'existence d'une boucle prix-salaire dans ces pays. En effet, si les salaires nominaux s'ajustent aux prix à la consommation, les prix intérieurs (prix de production et prix à la consommation) s'ajustent à leur tour aux hausses de salaires avec un décalage peut-être plus important.

La productivité du travail agit sur la formation des salaires en République tchèque et en Hongrie. Pour la Pologne, un trend temporel remplace la variable productivité dans l'équation de formation des salaires dans l'industrie manufacturière.

Tableau 5 : Relations pour les salaires dans l'industrie manufacturière de 1993-1 à 1997-3

$$
\log (W)=\beta \log (P C)+\sigma \log (P R O D)+\varphi T E M P S+C
$$

\begin{tabular}{|l|c|c|c|}
\hline & $\begin{array}{c}\text { Hongrie } \\
(1)\end{array}$ & $\begin{array}{c}\text { Pologne } \\
(2)\end{array}$ & $\begin{array}{c}\text { Rép. tchèque } \\
(3)\end{array}$ \\
\hline prix de consommation & 0,86 & 0,73 & 1 \\
& $(29,7)$ & $(10,98)$ & $x$ \\
\hline productivité du travail & 0,37 & $(2,4)$ & $\begin{array}{c}1,969 \\
(21,54)\end{array}$ \\
\hline temps & $x$ & 0,00999 & $x$ \\
& & $(2,24)$ & 0,0019 \\
constante & 0,25 & $-1,06$ & $0,36)$ \\
\hline SER & $(56,9)$ & $(-1,8)$ & 0,01455 \\
\hline$R^{2}$ corrigé & 0,0099 & 0,0109 & 0,9666 \\
\hline$D W$ & 0,999 & 0,998 & 1,64 \\
\hline
\end{tabular}

(1) En Hongrie, le prix de consommation est lissé sur quatre trimestres (de -5 à -2 trimestres), la productivité est lissée sur 9 trimestres (de -8 à 0 ).

(2) En Pologne, le prix de consommation est lissé sur neuf trimestres (de -8 à 0 trimestre)

(3) Estimation effectuée sur la période 1993-3 à 1997-3. 
Source : FMI, PEO décembre 1997, séries A de l'OCDE, Régressions économétriques de C. Baulant. 
b) Estimation des fonctions de commerce extérieur en volume des 3 pays

Les trois pays de l'Est se caractérisent par des déséquilibres de leur solde commercial. Le déficit commercial atteint en 1997 plus de 10\% du PIB en Pologne, 8\% en République tchèque et $6 \%$ en Hongrie. Pour ce pays, le déficit se réduit continûment depuis 1994. C'est aussi en Hongrie où la demande intérieure augmente le moins vite à la suite des diminutions de salaires réels.

Les trois pays se caractérisent par des taux d'ouverture croissants qui ont facilité le processus de rattrapage des économies de marché. L'ouverture croissante de ces pays a entraîné une plus grande spécialisation, davantage de concurrence par les prix et surtout une augmentation de la qualité des produits vendus à l'extérieur.

Ces économies à forte croissance de la demande intérieure auront sans doute durablement des importations qui augmenteront à un rythme élevé. La hausse des exportations est nécessaire pour permettre à ces pays de poursuivre ce processus de rattrapage. Les importations en biens d'équipement et en biens de consommation indiquent la nature de cette dépendance et nécessitent que l'on se concentre sur l'industrie manufacturière où ces évolutions sont encore plus marquées. La hausse de la demande intérieure se traduit pourtant, non seulement par une demande accrue d'importation, mais également par une demande accrue pour la production locale qui peut freiner le dynamisme des exportations.

\section{Les volumes d'exportation des produits manufacturés:}

Les fonctions d'exportations de produits manufacturés ont été estimées à l'aide de la compétitivité-prix et d'un trend temporel. Il n'a pas été possible de faire apparaître l'influence de la "demande mondiale" calculée par la somme pondérée des PIB étrangers ${ }^{19}$ (pondérée par la structure des exportations des pays de l'Est).

Les élasticités-prix apparaissent élevées en République tchèque et en Hongrie (1,89 et 1,75 respectivement). L'élasticité-prix de la Pologne est plus faible $(0,88)$. La compétitivité-prix influence les exportations de produits manufacturés avec un trimestre de retard en République tchèque et deux trimestres de retard pour les deux autres pays. Les indicateurs de compétitivité-prix retenus sont hétérogènes. Ce sont la compétitivité des prix d'exportation tous produits pour la République tchèque, la compétitivité des coûts salariaux unitaires pour la Pologne et les termes de l'échange de l'industrie manufacturière pour la Hongrie.

Les volumes d'importation des produits manufacturés :

Les fonctions d'importation des produits manufacturés ont été estimées à l'aide de

19 Il n'a pas été possible non plus de faire apparaître l'influence d'un véritable indicateur de "demande mondiale" (somme pondérée par le poids des pays dans les exportations des pays de l'Est des importations de produits manufacturés des 10 principaux pays partenaires). 
la la compétitivité-prix et de la demande intérieure (le PIB). Les élasticités-revenus apparaissent, dans nos estimations, plus élevées en République tchèque qu'en Hongrie ou en Pologne.

Les élasticités-prix à l'importation sont moins élevées que celles à l'exportation. L'élasticité-prix est plus grande en République tchèque $(1,09)$. Les élasticités-prix de la Hongrie et de la Pologne sont plus faibles (0,51 et 0,36 respectivement). Les indicateurs de compétitivité-prix retenus dans l'équation d'importation sont également hétérogènes. En République tchèque, un véritable indicateur de compétitivité-prix à l'importation (Prix d'importation sur le prix de production) a pu être mis en évidence et possède un coefficient élevé. Pour la Hongrie et la Pologne, nous avons dû utiliser des indicateurs de compétitivité basés sur les coûts salariaux unitaires de l'ensemble de l'économie. Compte tenu de la faible élasticité-prix des importations polonaises, la dévaluation du zloty au début de l'année 1998 ne devrait pas permettre un redressement du solde commercial en Pologne. Les importations polonaises seront orientées à la hausse tant que ne sera pas maîtrisé le boom de la demande intérieure. La forte hausse de la demande intérieure se traduit en effet par une vive progression des importations de la Pologne (biens d'équipement et biens de consommation). Il n'existe pas encore aujourd'hui de substituts locaux adéquats aux produits fournis par les importations (biens d'équipement et automobile).

\section{Tableau 6-A : Estimations des volumes d'exportation de produits manufacturés sur la période 1993-3 à 1997-3 :}

$$
\log (X)=a T E M P S+\varepsilon x \log \left(P^{*}+e-P\right)+C
$$

\begin{tabular}{|l|c|c|c|}
\hline & Hongrie & Pologne & rép tchèque \\
\hline Compétitivité prix ou coût (1) & 1,751 & 0,881 & 1,89 \\
& $((3,1)$ & $(2,8)$ & $(3,3)$ \\
\hline Temps & 0,0340 & 0,0509 & 0,04135 \\
& $(12,9)$ & $(8,00)$ & $(7,8)$ \\
\hline constante & $-4,35$ & $-6,42$ & $-5,19$ \\
& $(-12,8)$ & $(-8,0)$ & $(-7,6)$ \\
\hline SER & 0,03433 & 0,0373 & 0,0535 \\
\hline$R 2$ corrigé & 0,9449 & 0,9563 & 0,8709 \\
\hline DW & 1,1014 & 0,348 & 1,113 \\
\hline
\end{tabular}

(1) En Pologne, la compétitivité des coûts salariaux unitaires est lissée sur deux trimestres (de -1 à $0)$. En République tchèque, on a pris la compétitivité-prix des exportations totales retardée d'un trimestre. En Hongrie, on a utilisé les termes de l'échange lissés sur deux trimestres (-2 et -1).

Source: FMI, OCDE, Perspectives économiques de l'OCDE décembre 1997, Régressions économétriques C. Baulant. 
Tableau 6-b : Estimations des volumes d'importation de produits manufacturés sur la période 1993-3 à 1997-3 :

\begin{tabular}{|l|c|c|c|}
\multicolumn{4}{|c}{$\log (M)=\mu \log (P I B)-\varepsilon m \log (P M-P)+C$} \\
\hline & Hongrie & Pologne & Rép tchèque \\
& & & 5, \\
\hline Demande intérieure $(P I B)$ & 3,76 & 3,44 & 5,80 \\
& $(8,82)$ & $(12,1)$ & $(22,9)$ \\
\hline Compétitivité prix ou coût $(1)$ & 0,51 & 0,36 & 1,09 \\
& $(4,68)$ & $(1,71)$ & $(12,4)$ \\
\hline constante & $-55,42$ & $-37,71$ & $-78,87$ \\
& $(-8,83)$ & $(-12,1)$ & $(-22,8)$ \\
\hline SER & 0,03112 & 0,02149 & 0,05369 \\
\hline$R 2$ corrigé & 0,8284 & 0,9948 & 0,9766 \\
\hline$D W$ & 1,308 & 1,275 & 0,921 \\
\hline
\end{tabular}

(1) En Pologne et en Hongrie, on a utilisé la compétitivité des coûts salariaux unitaires instantanée. En République tchèque, on a retenu un véritable indicateur de compétitivité des prix intérieurs (prix d'importation/prix de production).

(2) Estimation de 1993-1 à 1997-3.

Source : FMI, OCDE, Perspectives économiques de l'OCDE décembre 1997, Régressions économétriques C. Baulant.

Pour les trois pays de l'Est, le théorème des élasticités critiques est vérifié (tableau 6-C). Une dévaluation améliore la balance commerciale du pays. La somme des élasticités-prix est élevée en République tchèque $(2,98)$ et indique une forte influence de la compétitivité-prix tant à l'exportation qu'à l'importation. La détérioration de la compétitivité-prix dans ce pays pourrait expliquer la forte dégradation de sa balance commerciale. Il faut noter que la dégradation du solde commercial en 1996 s'expliquait par la forte poussée des importations (qui ont augmenté trois fois plus vite que les importations). Cependant, $75 \%$ de ces importations étaient destinées à l'équipement du secteur manufacturier. Aussi, le déficit commercial s'explique par un manque de compétitivité-prix et par un rééquipement de l'industrie manufacturière. Un débat s'est alors engagé pour savoir s'il fallait mener une politique visant à augmenter fortement la productivité tchèque ou une politique de soutien à l'exportation. En créant dès 1995, la "Ceska Exportni Banka" (banque d'Etat), la seconde politique a été largement suivie en République tchèque (Blaha [1996]). L'amélioration récente de la compétitivité-prix tchèque depuis mai 1997 pourrait expliquer la réduction du déficit commercial en 1997 et 1998. En Pologne, la compétitivité-prix joue plus faiblement (avec une somme des élasticités-prix de 1,24). La dégradation du solde commercial s'expliquerait surtout par l'influence de l'élasticité-revenu pour les importations et l'influence d'un trend temporel pour les exportations. La Hongrie se situe dans une situation intermédiaire avec la somme des élasticités-prix qui atteint 2,26. 
Tableau 6-C : Théorème des élasticités critiques et condition Marshall-Lerner

\begin{tabular}{|c|c|c|c|c|c|c|c|c|}
\hline & $\varepsilon x$ & $\varepsilon m$ & $\begin{array}{l}\frac{\text { théorème }}{\text { des élast. }} \\
\text { critiques } \\
\frac{c x+\varepsilon m>1}{}\end{array}$ & $\alpha x$ & $\alpha m$ & $\begin{array}{c}\frac{\text { cond } M L}{S=\eta>0} \\
(\text { pour } b=1)\end{array}$ & $\begin{array}{c}b \\
e n \\
1994\end{array}$ & $\begin{array}{c}\frac{\text { cond } M L}{S>0}: \\
(\text { pour } b= \\
b \text { de 1994) }\end{array}$ \\
\hline $\begin{array}{l}\text { République } \\
\text { tchèque }\end{array}$ & 1,89 & 1,09 & 2,98 & 0,634 & 0,826 & 1,40 & 0,96 & 1,34 \\
\hline Hongrie & 1,751 & 0,514 & 2,27 & 0,766 & 0,528 & 0,92 & 0,82 & 0,75 \\
\hline Pologne & 0,881 & 0,360 & 1,24 & 0,745 & 0,778 & 0,47 & 1,04 & 0,49 \\
\hline
\end{tabular}

où

$\alpha x$ désigne l'élasticité du prix d'exportation aux prix des concurrents étrangers,

$\alpha m$ celle du prix des importations aux prix des concurrents,

ex l'élasticité-prix des exportations,

Em l'élasticité-prix des importations.

A production donnée, le solde commercial des produits manufacturés s'améliore après une dévaluation si

$$
\begin{gathered}
S=b[(\varepsilon x(1-\alpha x)+\alpha x)-(1-\varepsilon m) \alpha m]>0 \\
S=b(\eta)>0
\end{gathered}
$$

Avec $b$ le taux de couverture en valeur, $\eta=[(\varepsilon x(1-\alpha x)+\alpha x)-(1-\varepsilon m) \alpha m]$

Source :PEO juin 1998, régressions économétriques des tableaux 6-A et 6-B.

Tableau 6-D : Effet d'une dépréciation réelle de 10\%sur le taux de croissance du PIB (Y) et la balance commerciale $(\mathrm{Z1}, \mathrm{Z2})$ pour une dépréciation réelle de $10 \%$

\begin{tabular}{|l|c|c|c|c|c|c|}
\hline & $\begin{array}{c}\lambda \\
\text { en } \\
1994\end{array}$ & $\begin{array}{c}b \\
\text { en } \\
1994\end{array}$ & $\begin{array}{c}a \\
\text { en } \% \\
1996\end{array}$ & $\begin{array}{c}\Delta Y \\
(9)\end{array}$ & $\begin{array}{c}\Delta Z 1 \\
(10)\end{array}$ & $(11)$ \\
\hline République tchèque & 0,720 & 0,96 & 28,7 & 2,15 & 0,45 & 0,30 \\
\hline Hongrie & 0,739 & 0,82 & 24,8 & 1,78 & 0,62 & 0,08 \\
\hline Pologne & 0,784 & 1,04 & 15,9 & 1,01 & 0,21 & 0,271 \\
\hline
\end{tabular}

où

$\Delta Y$ désigne l'accroissement du PIB en volume à la suite d'une dépréciation réelle du change de 10\%. équation (9). $\Delta Z 1$ (ou $\Delta Z 2$ ) l'accroissement du solde commercial (en \% du PIB) à la suite d'une dépréciation réelle du change de $10 \%$ lorsque la production varie $(\Delta Y), \Delta Z 1$ pour un taux de couverture de 1, $\mathrm{Z} 2$ pour le taux de couverture observé en 1994, équations (10) et (11).

$q$ est le taux de change réel effectif

$\lambda$ la propension à dépenser a est le degré d'ouverture des échanges commerciaux des pays d'Europe centrale et orientale vis à vis de 17 pays de l'OCDE, b est le taux de couverture en valeur.

Source : PEO juin 1998, tableaux 3, 4, 6-A et 6-B. 
Tableau 6-E : Effet d'une dépréciation nominale de 10\%sur les prix (p) et le taux de change réel (q), le taux de croissance du PIB (Y) et de la balance commerciale (Z1 et z2)

\begin{tabular}{|l|c|c|c|c|c|c|c|c|}
\hline & $\begin{array}{c}\lambda \\
\text { en } \\
1994\end{array}$ & $\begin{array}{c}b \\
\text { en } \\
1994\end{array}$ & $\begin{array}{c}a \\
\text { en } \% \\
1996\end{array}$ & $\begin{array}{c}\Delta \boldsymbol{p} \\
\mathbf{( 1 5 )}\end{array}$ & $\begin{array}{c}\Delta \boldsymbol{q} \\
\mathbf{( 1 6 )}\end{array}$ & $\Delta Y$ & $\Delta Z 1$ & $\Delta Z 2$ \\
\hline $\begin{array}{l}\text { République } \\
\text { tch. }\end{array}$ & 0,720 & 0,96 & 28,7 & $\mathbf{1 0}$ & 0 & 0 & 0 & 0 \\
\hline Hongrie & 0,739 & 0,82 & 24,8 & 4,48 & $-5,52$ & 0,98 & 0,3 & $-0,16$ \\
\hline Pologne & 0,784 & 1,04 & 15,9 & 2,52 & $-7,36$ & 0,74 & 0,15 & 0,21 \\
\hline
\end{tabular}

où

$\Delta p$ désigne le taux de croissance des prix de production, équation (15)

$\Delta q$ le taux de croissance du taux de change réel effectif, équation (16)

$\Delta Y$ l'accroissement du PIB en volume à la suite d'une dépréciation réelle du change de $\Delta q$ Source : PEO juin 1998, tableaux 3, 4, 6-A et 6-B.

\subsection{Situation des trois pays vis-à-vis du taux d'ouverture}

Les estimations économétriques décrites ci-dessus permettent de quantifier les paramètres qui interviennent dans les équations (9), (10), (11), (15) et (16). Le tableau 7 ci-dessous résume les valeurs retenues pour les paramètres.

Tableau 7 : Coefficients pour les paramètres structurels

\begin{tabular}{|l|c|c|c|}
\hline \multicolumn{1}{|c|}{ Paramètres } & Pologne & République tchèque & Hongrie \\
\hline $\begin{array}{l}\text { Elasticités-prix et revenu } \\
\text { Du commerce extérieur } \\
\varepsilon_{\chi}\end{array}$ & 0,881 & & 1,89 \\
\hline$\varepsilon_{m}$ & 0,36 & 1,09 & 0,514 \\
\hline$\mu$ & 3,4 & 5,80 & 3,76 \\
\hline $\begin{array}{l}\text { Arbitrage compétitivité- } \\
\text { profitabilité } \\
\alpha_{\chi}\end{array}$ & 0,745 & 0,634 & 0,766 \\
\hline$\alpha_{m}$ d'indexation des & 0,778 & 0,826 & 0,528 \\
\hline $\begin{array}{l}\text { Degré } \\
\text { salaires et des prix } \\
\text { épargne intérieur }\end{array}$ & & & \\
$\beta$ & 0,78 & 1,0 & 0,86 \\
\hline$\gamma$ & 1,0 & 1,0 & 1,0 \\
\hline
\end{tabular}




\begin{tabular}{|l|l|l|l|}
\cline { 2 - 4 }$\lambda$ & 0,784 & 0,720 & 0,739 \\
\hline
\end{tabular}

On simule d'abord les équations (9), (10), (11) pour une dévaluation réelle du taux de change de $10 \%$. Cela suppose des politiques d'accompagnement qui parviennent à éviter ou à limiter la réaction des prix intérieurs à la dévaluation nominale. Les graphiques $\mathbf{4}$ et $\mathbf{5}$ montrent les effets comparés d'une même dévaluation réelle sur les trois pays pour la croissance et la balance commerciale, lorsque le taux d'ouverture varie de 1 à $50 \%$.

L'incidence sur la croissance est d'autant plus importante que le taux d'ouverture est plus élevé (graphique 4). Mais elle est fortement non linéaire. Augmentant très rapidement avec le taux d'ouverture lorsque celui-ci s'accroît à partir de niveau très bas, la sensibilité de la production à la dévaluation réelle devient presque constante pour des taux d'ouverture dépassant $30 \%$. En outre, les effets sont significativement différents selon les pays. Pour des taux d'ouverture voisins de $25 \%$, une dévaluation réelle de $10 \%$ entraîne une augmentation du PIB de $1 \%$ environ en Pologne, de 1,7\% en Hongrie et de $2 \%$ en République tchèque (tableau 6-D). La raison essentielle se trouve dans la faible élasticitéprix des exportations de la Pologne comparée à celle de ses partenaires (tableau 7).

Le graphique 5 montre les effets qu'aurait une dévaluation réelle de $10 \%$ sur la balance commerciale en valeur des trois pays sous l'hypothèse que cette dévaluation se produit à partir d'une situation initiale où la balance commerciale est équilibrée. Les trois pays réagissent de manières différentes. Le facteur structurel responsable de cette divergence est la différence des élasticités en valeur à l'exportation et à l'importation (équation 10). Ce facteur dépend à la fois des élasticités-prix des volumes d'exportation et d'importation et des comportements de marge à l'exportation et sur le marché intérieur.

En Pologne, l'amélioration de la balance commerciale atteint péniblement 0,2\% du PIB pour une dévaluation réelle de $10 \%$ au taux d'ouverture actuel de $16 \%$. Le solde commercial est très peu sensible à l'augmentation du taux d'ouverture au-delà du niveau actuel. En République tchèque, l'effet maximum est de $0,46 \%$ du PIB pour un taux d'ouverture de $20 \%$ et de $0,45 \%$ au taux d'ouverture actuel de $29 \%$. En Hongrie, au contraire, l'amélioration de la balance commerciale est croissante avec le taux d'ouverture pour la plage de variation étudiée en deçà de $50 \%$. On retrouve l'avantage de la Hongrie et de la République tchèque sur la Pologne grâce à des élasticités-prix supérieures à l'exportation (tableau 6-D). De plus, la sensibilité plus forte de la Hongrie que de la République tchèque provient du comportement de marge des importateurs sur le marché intérieur. La variation du taux de change est beaucoup moins répercutée dans les prix à l'importation en Hongrie qu'en République tchèque, alors que la répercussion dans les prix à l'exportation est presque la même. Il s'ensuit que pour une même dévaluation nominale les termes de l'échange s'améliorent en Hongrie, alors qu'ils se détériorent en République tchèque.

Lorsque la balance commerciale est déséquilibrée avant la dévaluation réelle, l'effet est beaucoup moins favorable. Les graphiques 6 et 7 simulent les variations de la balance commerciale en valeur avec le degré d'ouverture pour des taux de couverture 
initiaux des exportations par les importations respectivement de $90 \%$ et de $80 \%$. Plus le déficit initial est important, moins la dépréciation du taux de change réel a des effets favorables. Non seulement l'amélioration maximale se produit pour des taux d'ouverture plus faibles, mais au-delà de taux d'ouverture limités d'autant plus bas que le taux de couverture est faible, la variation de la balance commerciale est négative. Le déficit empire lorsque la monnaie se déprécie entrânant un cercle vicieux. On retrouve ici une observation bien connue des crises de change : le danger que se creusent des déficits trop importants dans des pays très ouverts sur l'extérieur. La hiérarchie des réactions des pays, qui dépend des facteurs structurels examinés ci-dessus, est bien sûr conservée. Ainsi le graphique 6 montre-t-il que, pour un taux de couverture initial de $90 \%$, le seuil du taux d'ouverture est de $23 \%$ en Pologne et $32 \%$ en République tchèque, supérieurs aux niveaux actuels de $16 \%$ et $29 \%$. Cependant ils en sont suffisamment proches pour que les gains sur la balance commerciale en valeur soient faibles. Lorsque la situation initiale est très dégradée, ce qui est représenté par un taux de couverture de $80 \%$, le graphique 7 montre que même la Hongrie se trouve dans une situation où sa balance commerciale ne s'améliore presque pas. Les deux autres pays sont pris dans un cercle vicieux, surtout la République tchèque dont le taux d'ouverture est très supérieur à celui de la Pologne.

Les graphiques 8 et 9 prennent en compte les effets de la répercussion des salaires et des prix intérieurs qui viennent réduire l'influence sur le taux de change réel d'une dévaluation de $10 \%$ du taux de change nominal. Ces effets dépendent des réponses croisées des salaires et des prix, c'est à dire des conditions de la répartition intérieure des revenus entre les entreprises et les salariés. Dans l'impossibilité d'estimer simultanément ces effets croisés avec les données dont on dispose, on a supposé que le taux de marge sur les coûts salariaux était rigide dans les trois pays. On a estimé les coefficients d'indexation des salaires sur les prix. Ces estimations font apparaître un coefficient qui n'est pas significativement différent de un en République tchèque. Il s'ensuit que dans ces pays la rigidité de la répartition est totale. Une dévaluation n'a alors aucun effet à long terme, ni sur la production, ni sur la balance commerciale en valeur (tableau 6-E). Cette rigidité peut justifier un ancrage nominal du taux de change. Dans les deux autres pays, il existe une flexibilité du salaire nominal, plus importante en Pologne. Il en résulte des effets d'une dévaluation nominale du taux de change sur le PIB et la balance commerciale. Toutefois, si on compare les graphiques 8 et 9 aux graphiques 4 et 5 , on remarque que les effets sont sensiblement amoindris. D'abord l'incidence sur la production n'est plus une fonction croissante du taux d'ouverture. Elle demeure positive mais atteint un maximum pour un taux d'ouverture relativement faible, autour de $17 \%$ en Pologne et de $15 \%$ en Hongrie. Cette incidence s'amenuise ensuite, au fur et à mesure que le degré d'ouverture augmente. Ensuite l'effet sur la balance commerciale est particulièrement spectaculaire pour la Hongrie. Le fort degré d'indexation des salaires réduit sensiblement l'amélioration de la balance commerciale suite à une dévaluation. Elle culmine à $0,24 \%$ du PIB pour une dévaluation de $10 \%$ correspondant à un taux d'ouverture de $12 \%$. Néanmoins le maximum est très plat, de sorte que l'effet est sensiblement le même au taux d'ouverture actuel de $25 \%$.

Les incidences de la dévaluation nominale sur le taux d'inflation et le taux de change réel sont décrites sur les graphiques 10 et 11 pour la Hongrie et la Pologne, pays 
pour lesquels la dévaluation a des effets réels. L'effet inflationniste de la dévaluation croît avec le taux d'ouverture. L'impact sur le taux de change réel est donc d'autant plus faible que le taux d'ouverture est plus élevé. L'impact inflationniste sur la Hongrie est légèrement plus fort que sur la Pologne parce que le degré d'indexation des salaires sur les prix est plus élevé. Une dévaluation nominale de $10 \%$ se répercuterait en une hausse des prix de 2,5\% en Pologne et de 4,2\% en Hongrie. 
Graphique 4 : Effet sur le PIB d'une dévaluation de $10 \%$ du taux de change réel

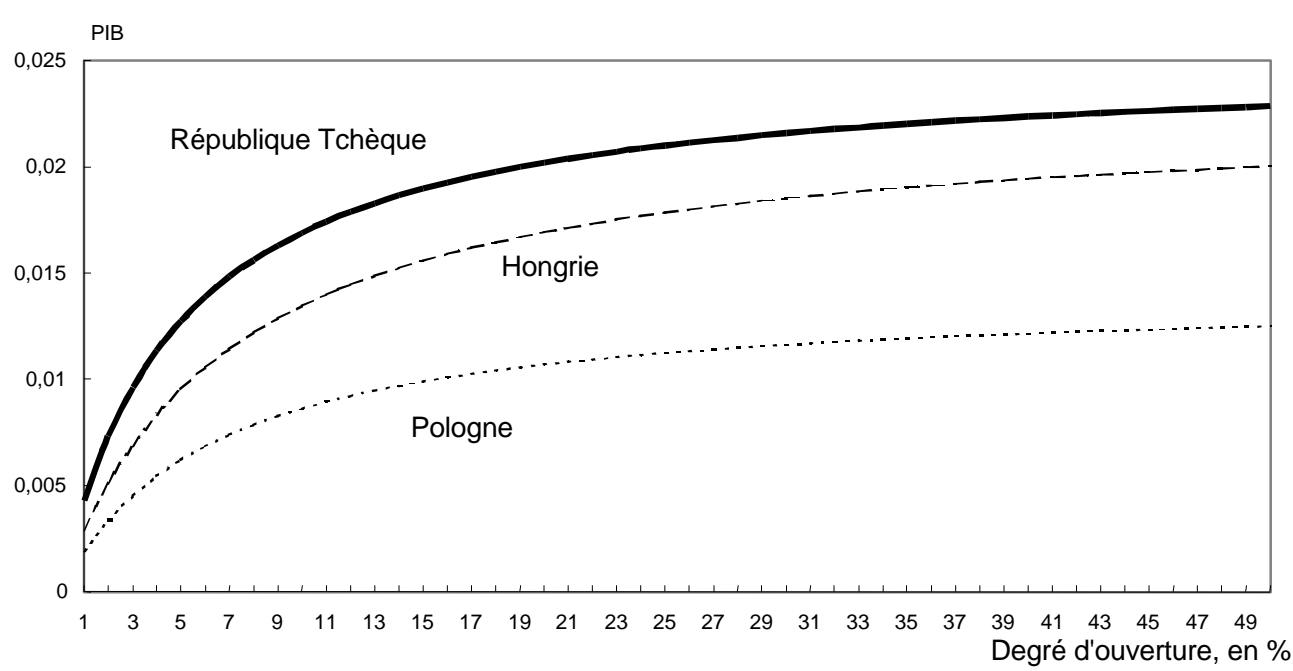

Graphique 5 : Effet sur la balance

d'une dévaluation de $10 \%$ du taux de change

avec un taux de couverture $=1$

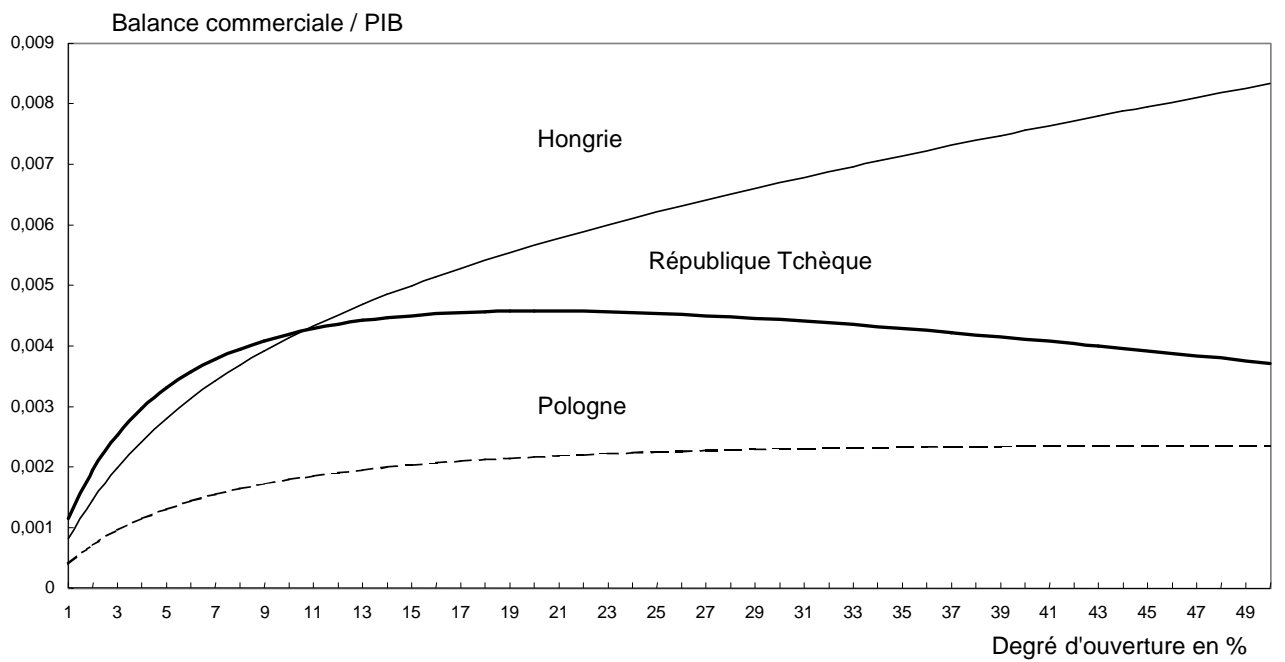


Graphique 6 : Effet sur la balance commerciale d'une dévaluation de $10 \%$ du taux de change réel avec un taux de couverture de 0,9

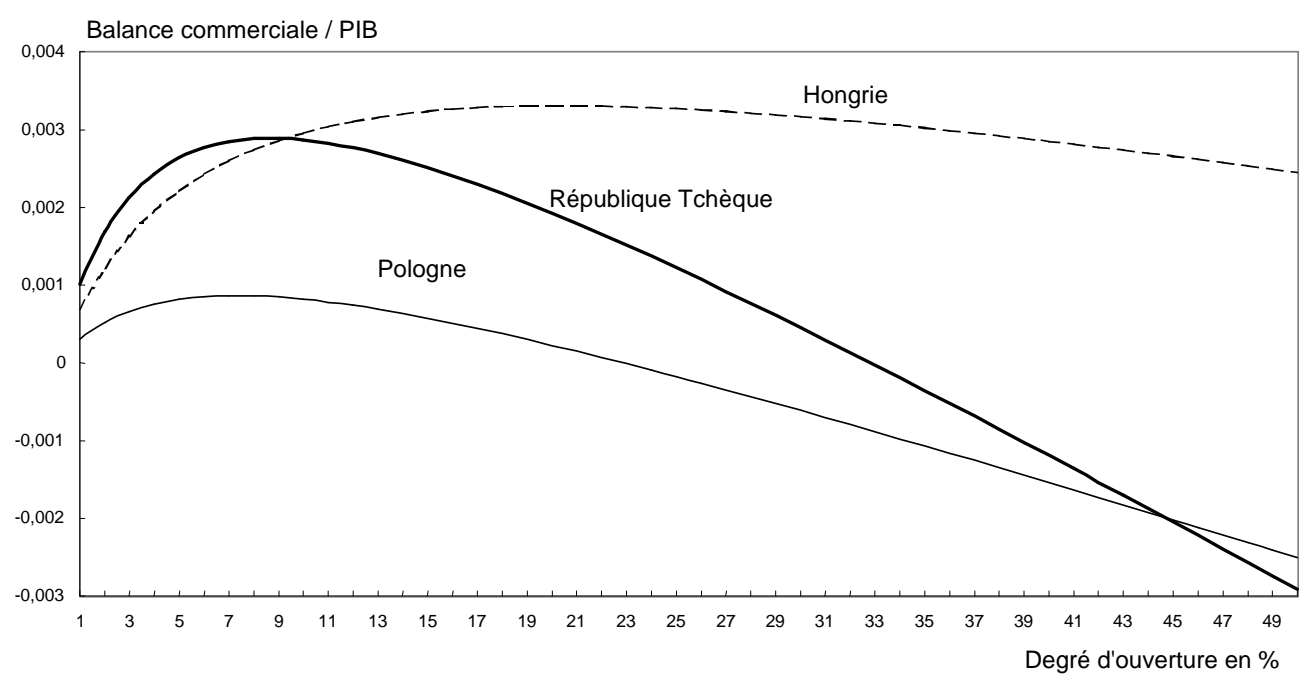

Graphique 7 : Effet sur la balance commerciale d'une dévaluation de $10 \%$ du taux de change réel avec un taux de couverture de 0,8

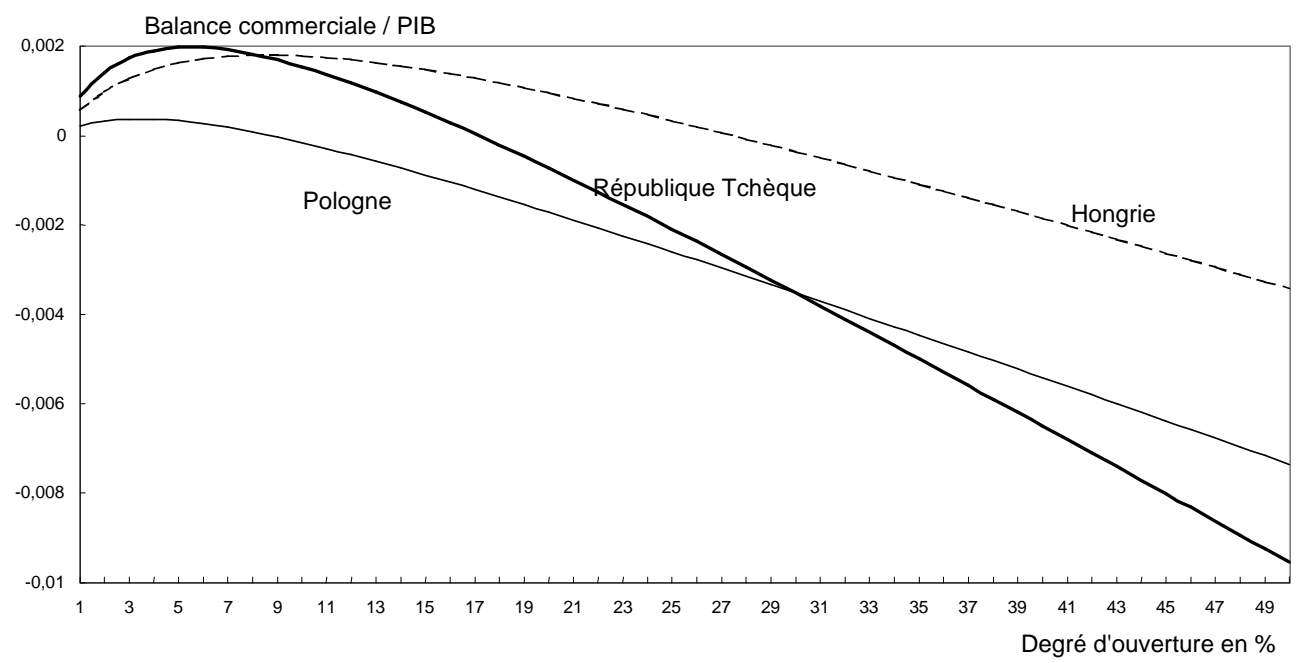




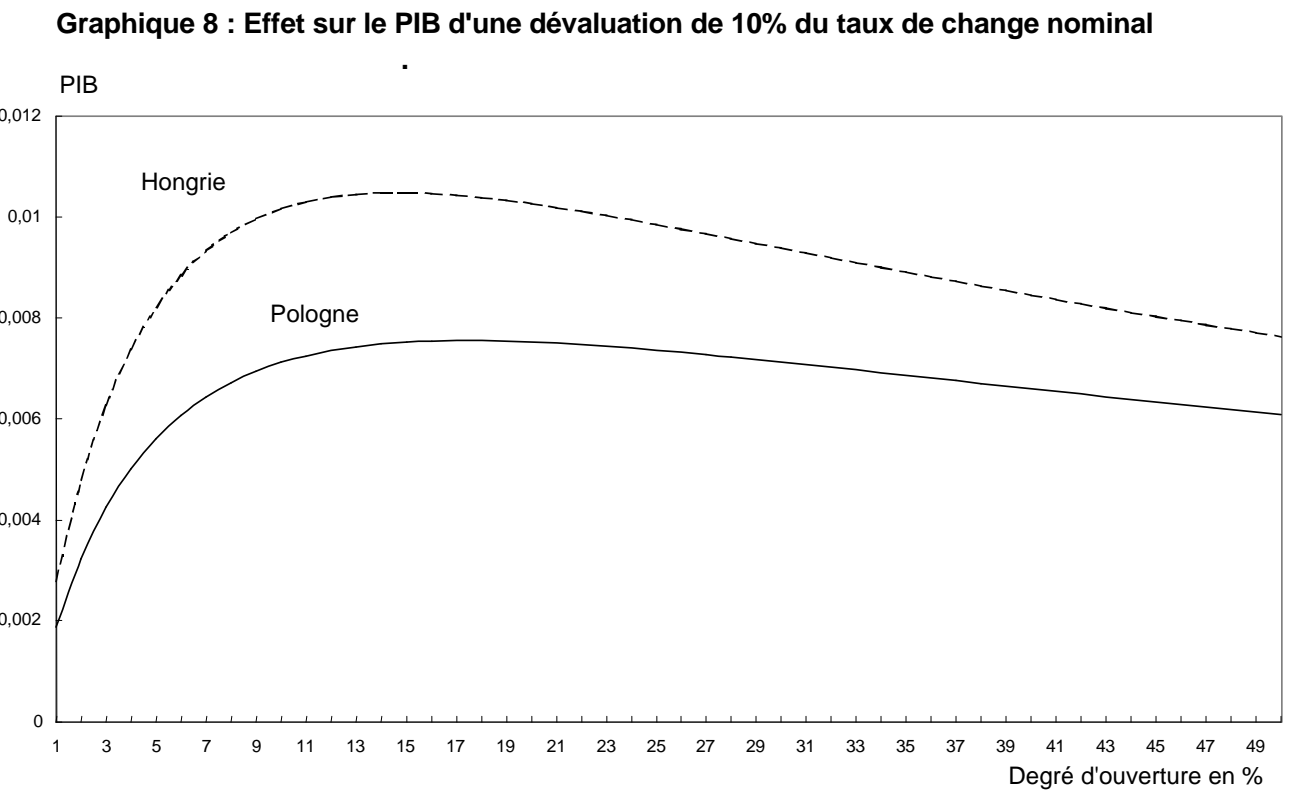

Graphique 9 : Effet sur la balance commerciale d'une dévaluation de $10 \%$ du taux de change nominal, taux de couverture $=0,9$ et 0,8 .

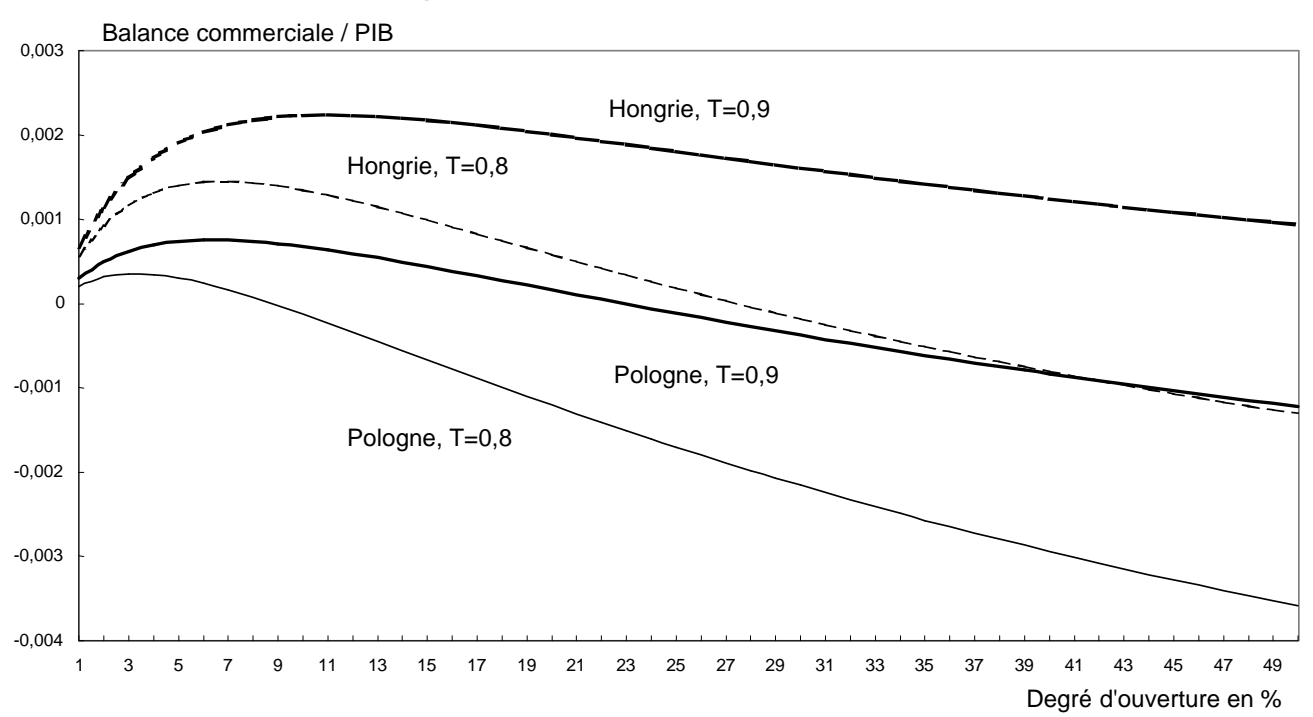


Graphique 10 : Effet sur les prix d'une dévaluation nominale de $10 \%$

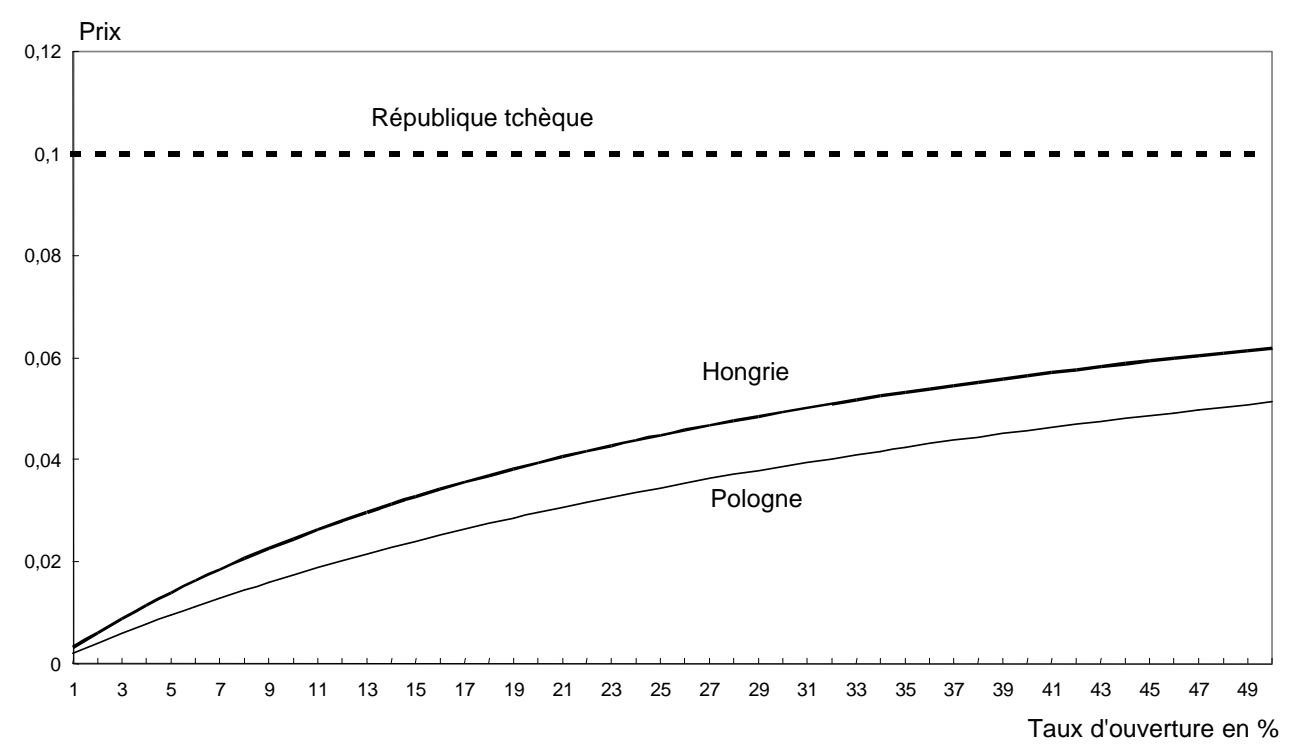

Graphique 11 : Effet sur le taux de change réel d'une dévaluation nominale de $10 \%$

Taux de change réel

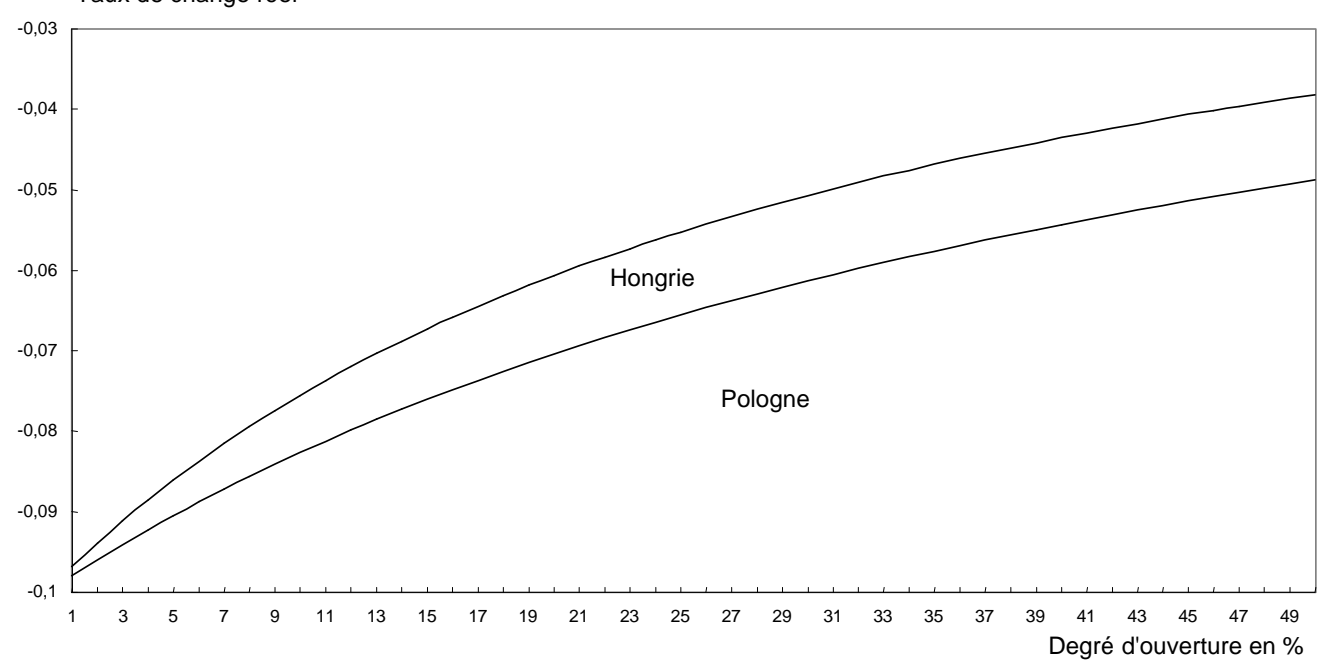




\section{LE CHOIX D'UN RÉGIME DE CHANGE}

Les crises de change qui ont éclaté récemment dans les pays émergents renforcent les interrogations sur le bon choix d'un régime de change. La monnaie ou le panier de monnaies de rattachement sont un élément important de ce choix. Elle doit être conforme à la structure des échanges commerciaux et financiers du pays, de façon à ce que le taux de change effectif puisse être contrôlé. Après l'UEM, l'ancrage à l'euro paraît le plus naturel d'autant plus que nombre de pays stabilisent déjà leur monnaie par rapport au mark. La structure de la dette et des échanges semble compatible avec ce choix (Bénassy et Lahrèche, 1998). Mais l'inflation des PECO excédant encore largement celle de la zone euro, un taux de change nominal fixe ne semble guère réalisable. Des régimes intermédiaires doivent être recherchés.

\subsection{Enjeux et modalités du choix}

Un régime de change est toujours dépendant des priorités de la politique économique. Si une règle de change nominal fixe est choisie, l'objectif est clairement de maintenir les prix intérieurs. La crédibilité de l'action du gouvernement peut en être améliorée. La fixité des changes nominaux peut être un moyen de faire baisser rapidement les anticipations d'inflation. En contrepartie, la politique monétaire perd son autonomie, sans que le respect de la contrainte externe se trouve garanti pour autant. Le risque principal réside dans la persistance des facteurs d'inflation interne, qui apprécient le taux de change réel. Dans la réalité, les pays adoptant un régime de taux de change fixe pour résoudre leur problème d'inflation sont généralement confrontés à une appréciation de leur taux de change réel, car la hausse des prix est souvent persistante. Cette appréciation réelle peut être bénéfique, car elle fait baisser les prix des importations et contribue donc à modérer l'inflation. Mais si elle est trop forte, l'appréciation réelle peut mener à une surévaluation de la monnaie dommageable à la compétitivité nationale et donc au commerce extérieur.

Le choix opposé, d'un taux de change purement flexible, n'est généralement pas souhaitable dans les pays en transition car il exige des marchés financiers profonds et diversifiés, ainsi qu'un système bancaire robuste. Sur des marchés financiers étroits, le flottement pur donne lieu à une instabilité du taux de change car une petite variation de l'offre et de la demande peut produire une grande variation des prix. La plupart des pays émergents, comme les pays en transition, ont adopté des régimes de change intermédiaires basés sur une flexibilité partielle des parités. Cela peut recouvrir aussi bien un taux de change flottant géré qu'une bande de fluctuations glissante, ou une zone cible large avec recours à des réalignements chevauchants. La ligne de conduite est de préserver l'ajustement réel, tout en signalant les intentions de la politique monétaire pour provoquer des entrées de capitaux. En effet l'ancrage du taux de change rassure les investisseurs internationaux en limitant les pertes potentielles sur la devise. Ces régimes permettent un compromis entre le contrôle de l'inflation et la compétitivité. Dans un régime de change 
intermédiaire, les autorités arbitrent continûment entre le souci de l'inflation et celui de la compétitivité. 
Les choix des ex-pays socialistes en matière de régime de change vont de la flexibilité totale à l'entière fixité, pour les pays ayant mis en place des currency boards. Le flottement libre pratiqué en Roumanie, en Albanie et dans les Etats les moins avancés de la CEI fait figure de pis-aller. On peut penser que ces pays n'avaient guère d'autre choix, car la faiblesse de leur économie et de leurs réserves de change aurait rendu difficile l'ancrage du change. A l'autre extrémité, les currency boards répondent à des situations critiques où la lutte contre l'inflation est devenue un enjeu primordial, qui fait préférer le renoncement à la souveraineté monétaire. L'Estonie, puis plus récemment la Bulgarie et la Bosnie Herzégovine ont ainsi fixé leur taux de change vis-à-vis du mark. La Lituanie a mis en place un système analogue vis-à-vis du dollar.

En dehors de ces cas extrêmes, la grande majorité des PECO ont adopté des régimes intermédiaires où le taux de change est géré sans être fixe. La Hongrie et la Pologne maintiennent leur change à l'intérieur de bandes glissantes, "crawling pegs", par rapport à un panier de monnaies. La Croatie et la République slovaque gèrent leur taux de change à l'intérieur d'une fourchette objectif, par rapport au mark pour la première et un panier de monnaies pour la seconde. C'est ce que faisait aussi la République tchèque avant la dévaluation de sa monnaie en mai 1997, qui l'a contrainte d'abandonner cette stratégie. La couronne tchèque fait maintenant l'objet d'un flottement géré visant à en stabiliser les fluctuations par rapport au mark allemand.

\subsection{Régime de change et tensions inflationnistes}

Le choix d'un régime de change doit tenir compte de la propension particulière à l'inflation constatée après le passage à l'économie de marché. La stabilisation de l'inflation pose en effet un problème particulier dans les PECO en raison du désajustement des prix initiaux. Le rattrapage des prix par rapport à ceux pratiqués dans les pays industriels voisins a créé une source d'inflation supplémentaire après le passage à l'économie de marché. Or ce rattrapage est loin d'être terminé, notamment en ce qui concerne les services.

La brusque ouverture de ces économies au moment où leur taux de change était sousévalué explique en partie le problème de l'inflation. En effet, en décomposant le prix à la consommation en sa composante interne et externe, on a :

(17) $\mathrm{p}_{\mathrm{c}}=(1-\mathrm{a}) \mathrm{p}+\mathrm{a} \mathrm{p}_{\mathrm{m}}$,

où $\mathrm{p}_{\mathrm{c}}$ désigne l'indice des prix à la consommation, $\mathrm{p}$ les prix de production intérieurs, $\mathrm{p}_{\mathrm{m}}$ le prix des importations et a le degré d'ouverture. (Comme précédemment les variables sont prises en logarithme).

En reprenant l'équation (7), le prix des importations s'exprime en fonction de l'arbitrage entre les prix étrangers multipliés par le taux de change et les prix internes :

(7) $\mathrm{p}_{\mathrm{m}}=\alpha_{\mathrm{m}} \mathrm{ep}^{*}+\left(1-\alpha_{\mathrm{m}}\right) \mathrm{p}$,

En incorporant (7) dans (17) et en différenciant, on peut décomposer l'inflation en trois termes :

(18) $\Delta \mathrm{p}_{\mathrm{c}}=\Delta \mathrm{a} \alpha_{\mathrm{m}}(\mathrm{ep} * \mathrm{p})+\left(1-\mathrm{a} \alpha_{\mathrm{m}}\right) \Delta \mathrm{p}+\mathrm{a} \alpha_{\mathrm{m}} \mathrm{p}^{*} \Delta \mathrm{e}$,

Le premier terme est négligé habituellement car le degré d'ouverture d'une économie est 
généralement supposé constant. Dans le cas des PECO cependant, cette hypothèse ne tient pas car le degré d'ouverture a beaucoup varié sur la première période. L'étude des incidences de cette variation a fait l'objet de la partie III-3. Or du fait de la sous-évaluation initiale, les prix des importations ep* étaient plus chers que les prix nationaux.

Le premier terme $\Delta a \alpha_{m}\left(e p^{*}-p\right)$ est donc positif, ce qui montre que l'augmentation du degré d'ouverture a contribué à l'inflation, au moins dans un premier temps.

Par contre, le troisième terme : $a \alpha_{m} \mathrm{p}^{*} \Delta \mathrm{e}$, qui indique l'effet de la variation des prix des importations devrait plutôt jouer à la modération de l'inflation, lorsque le taux de change réel s'est apprécié régulièrement.

Le rôle de la désinflation importée se voit très bien sur le tableau et le graphique suivant pour les trois pays considérés. En République tchèque, la forte appréciation du taux de change réel (de 31,5\% de 1994 à 1997) a joué un rôle important dans la désinflation (tableau 8 et graphique 12). Ceci est aussi vrai en Pologne. L'appréciation réelle de 28,7\% sur cette période a contribué à faire baisser l'inflation de 32,2\% en 1994 à 14,9\% en 1997. Au contraire, en Hongrie, où le taux de change réel s'est déprécié, l'inflation n'a pratiquement pas baissé.

Tableau 8 : Inflation et taux de change réel (en variation)

\begin{tabular}{|l|r|c|c|c|c|c|}
\hline & \multicolumn{2}{|c|}{ Hongrie } & \multicolumn{2}{c|}{ République tchèque } & \multicolumn{2}{c|}{ Pologne } \\
\hline & 1994 & 1997 & 1994 & 1997 & 1994 & 1997 \\
\hline prix à la consommation & 19,8 & 18,1 & 10,7 & 8,8 & 32,2 & 14,9 \\
\hline prix des importations & 15,6 & 16,8 & 2,2 & 8,1 & 27,1 & 12,9 \\
\hline $\begin{array}{l}\text { Appréciation du taux de } \\
\text { change réel (1) de 1994 à 1997 }\end{array}$ & $-10,3 \%$ & \multicolumn{2}{|c|}{$31,5 \%$} & \multicolumn{2}{|c|}{$28,7 \%$} \\
\hline
\end{tabular}

(1) Taux de change réel effectif calculé avec les coûts salariaux unitaires, variation cumulée de 1994 à 1997 (tableau 2c).

Source : Prix à la consommation, Perpectives économiques de l'OCDE, juin 1998.

La République tchèque est l'un des pays qui a réussi le mieux à combattre l'inflation. La politique de change fixe à l'intérieur de bandes de fluctuations suivie jusqu'en mai 1997 l'y a aidée. L'inflation était tombée aux alentours de 7\% l'an à l'époque. (Depuis la dévaluation, elle est naturellement remontée). Il est intéressant de constater que des performances similaires ont été obtenues par la République slovaque et la Croatie, qui avaient adopté le même type de régime de change. Leur inflation est redescendue aux alentours de 6\% et 4\% respectivement fin 1997.

Les résultats ont été moins bons en Hongrie et en Pologne, qui ont adopté un système de "crawling band", et ont procédé à des dévaluations rampantes de manière à limiter l'appréciation réelle de leur monnaie. Dans ces cas, la politique de change n'a pas servi à combattre aussi efficacement l'inflation. L'inflation était encore de $15 \%$ l'an en 
Pologne en 1997 et de $18 \%$ en Hongrie. La Pologne a néanmoins fait mieux que la Hongrie en termes de désinflation car elle a laissé son taux de change réel s'apprécier davantage.

Graphique 12 : Prix de consommation et prix d'importations en Pologne, en République tchèque et en Hongrie (1993 - 1998)
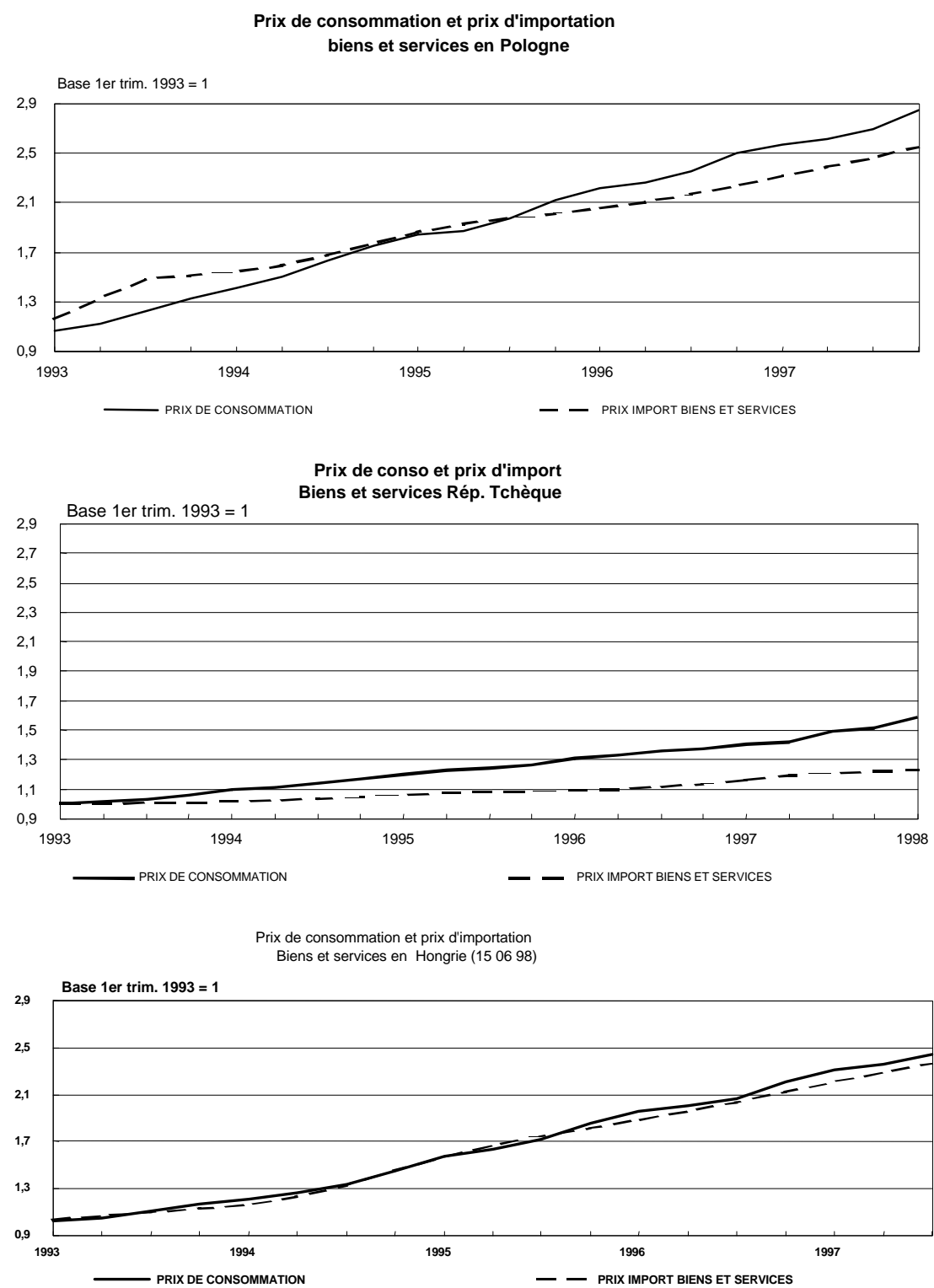
Les régimes de changes totalement fixes dans le cas d'un 'currency board', comme l'Estonie, la Lituanie depuis 1994, ont conduit à des succès dans la lutte contre l'inflation, mais aussi à une forte appréciation du taux de change réel. En trois ans, de 1994 à 1997, l'inflation est tombée de $72 \%$ à $9 \%$ en Lituanie, et de $48 \%$ à $12 \%$ en Estonie Ces pays ayant retrouvé un certain équilibre dans leurs prix se préparent à sortir de ce système afin de restaurer leur compétitivité.

Dans la plupart des pays d'Europe centrale et orientale, la gestion du taux de change a permis de modérer les anticipations d'inflation. Il convient de distinguer deux périodes. D'abord, le passage à l'économie de marché a déclenché une poussée massive d'inflation, voire d'hyperinflation (avec quelques exceptions : la Tchécoslovaquie et la Hongrie). Dans cette période, l'ancrage du taux de change nominal a été recherché pour ses effets anti-inflationnistes. L'appréciation du taux de change réel était alors considérée comme bénéfique. Dans une seconde période, l'inflation a pu être contenue en deçà de 20 à $40 \%$ l'an. A ce moment, le souci de limiter les pertes de compétitivité est apparu.

\subsection{Régime de change et balance commerciale}

Dans la plupart des PECO, l'ancrage du taux de change nominal s'est traduit par une appréciation du taux de change réel car l'inflation est restée forte. Parallèlement les déficits extérieurs se sont creusés. Le déficit commercial est passé de $0,9 \%$ du PIB à 4,4\% en République tchèque entre 1994 et 1997 et de 0,6\% à 10,8\% en Pologne (tableau 9). Comme ces deux pays ont connu des appréciations réelles de l'ordre de $30 \%$ sur cette période, on peut donc se demander dans quelle mesure la dégradation du déficit est liée à la politique de change. 
Tableau 9 : Balance commerciale et impact du taux de change

\begin{tabular}{|c|c|c|c|c|c|c|}
\hline & \multicolumn{2}{|c|}{ Hongrie } & \multicolumn{2}{|c|}{$\begin{array}{l}\text { République } \\
\text { tchèque }\end{array}$} & \multicolumn{2}{|c|}{ Pologne } \\
\hline & 1994 & 1997 & \begin{tabular}{|l|}
1994 \\
\end{tabular} & 1997 & 1994 & 1997 \\
\hline $\begin{array}{l}\text { Appréciation du taux de change } \\
\text { réel (1) de } 1994 \text { à } 1997\end{array}$ & \multicolumn{2}{|c|}{$-10,3 \%$} & \multicolumn{2}{|c|}{$31,5 \%$} & \multicolumn{2}{|c|}{$28,7 \%$} \\
\hline $\begin{array}{l}\text { Balance commerciale, } \\
\text { en } \% \text { du PIB }\end{array}$ & $-3,7 \%$ & $-1,7 \%$ & $-0,9 \%$ & $-4,4 \%$ & $-0,6 \%$ & $-10,8 \%$ \\
\hline $\begin{array}{l}\text { Effet du taux de change réel sur } 1 \\
\text { balance commerciale, en \% du } \\
\text { PIB de } 1994 \text { à } 1997 \text { (2) }\end{array}$ & \multicolumn{2}{|c|}{$\begin{array}{c}+0,1 \% \\
(=-10,3 \mathrm{x}-(0,1 \mathrm{x} 0,1))\end{array}$} & \multicolumn{2}{|c|}{$\begin{array}{c}-1,5 \% \\
(=31,5 \mathrm{x}-(0,5 \mathrm{x} 0,1))\end{array}$} & \multicolumn{2}{|c|}{$\begin{array}{c}-0,6 \% \\
(=28,7 \mathrm{x}-(0,2 \mathrm{x} 0,1))\end{array}$} \\
\hline
\end{tabular}

(1) Taux de change réel effectif calculé avec les CSU, variation cumulée de 1994 à 1997 (tableau 2c).

(2) Calculés avec les simulations de la partie précédente en prenant les taux d'ouverture et de couverture de 1994 (respectivement 19\%,26\%,15\% et $0,8,1,1$ ).

Source : Balance commerciale, Perpectives économiques de l'OCDE, juin 1998.

Les simulations menées précédemment permettent de chiffrer l'impact du taux de change sur le déficit commercial. Les résultats montrent que cet impact est assez modeste. L'appréciation du taux de change réel ne suffit pas à expliquer la montée des déficits extérieurs constatés dans ces pays. Cependant la Hongrie, qui a laissé son taux de change réel se déprécier, a réussi à réduire son déficit commercial, contrairement aux deux autres pays considérés. Les déficits constatés dans les PECO résultent aussi de la croissance de la demande intérieure plus soutenue qu'à l'étranger. Il sont cohérents avec l'adaptation encore incomplète de l'appareil de production aux besoins du marché international. Le déficit est en effet la contrepartie comptable inévitable des afflux de capitaux entrant dans les PECO et qui sont nécessaires à la modernisation des capacités de production.

\section{CONClusion}

Les trois pays étudiés vont entrer dans une nouvelle phase qui est la préparation de leur participation à l'Union européenne. C'est une gageure car leur niveau de développement est plus bas que celui du Portugal et de l'Irlande au moment de leur entrée dans l'Union. Cependant, les énormes progrès effectués par ces deux pays depuis leur intégration sont un gage d'optimisme.

Deux facteurs ont joué un grand rôle dans la modernisation de ces économies. En premier lieu, les fonds structurels alloués par le budget communautaire et les financements de la banque Européenne d'investissement ont permis d'effectuer des investissements collectifs. En second lieu, l'apport d'investissements directs dans les entrées de capitaux a accéléré les transformations industrielles. La Hongrie et la République tchèque ont déjà bénéficié d'investissements directs importants. Mais la dégradation des infrastructures collectives dans les trois pays demeure un handicap sérieux pour la compétitivité. La participation à l'Union Européenne leur donnera droit à des fonds structurels dont l'efficacité a été avérée dans les pays qui en ont bénéficié. Un autre facteur structurel qui 
est un handicap particulier de la Hongrie et de la République tchèque, alors que la Pologne a su résoudre le problème, est l'état de leur système financier qui demeure grevé de mauvaises créances. Cependant, ces banques sont peu endettées à l'étranger. Leur bilan est donc peu affecté par une hausse brutale du taux de change.

Du point de vue macro-économique, la République tchèque a un taux d'inflation relativement faible, la Pologne a commencé à le faire baisser significativement, ce qui n'est pas le cas de la Hongrie. En tout état de cause, les taux d'inflation des trois pays sont très au-dessus de la norme européenne qui est excessivement rigoureuse. Il ne peut donc être question que ces pays entrent dans un accord de change quelconque du type SME. Chacun va devoir continuer à gérer son dilemme entre compétitivité et désinflation selon la méthode qui lui parait la plus convenable. Le choix se limite d'ailleurs entre le flottement administré et le glissement d'un taux de change cible autour duquel sont tolérées des fluctuations à l'intérieur de marges larges. Cependant, une innovation naturelle et raisonnable serait de passer à un ancrage homogène des pays candidats à l'entrée dans l'Union européenne sur l'euro, en lieu et place des paniers hétéroclites utilisés jusqu'ici.

La vulnérabilité de leurs balances courantes à des entrées excessives de capitaux qui sont sensibles à des chocs financiers se produisant dans n'importe quel pays émergent est une menace permanente résultant de leur choix prématuré d'ouverture financière. Cette fragilité contraint la politique monétaire d'une manière intempestive, surtout dans des situations d'excès de demande interne. L'offre compétitive étant encore fortement limitée, les poussées excédentaires et les détériorations des balances courantes vont demeurer les soucis principaux de la politique macro-économique, alors que les mouvements de capitaux sont libres.

En l'absence de contrôles efficaces, il est difficile à la politique économique de naviguer entre les écueils de l'excès de demande et du déficit extérieur. Les à coups de la conjoncture depuis 1994 perturbent la modernisation qui a besoin d'un cercle vertueux entre l'investissement productif, les progrès de productivité, l'augmentation de la compétitivité et l'accroissement du degré d'ouverture. Le taux de change réel est la variable cruciale de ce cercle vertueux. En admettant que la phase actuelle de la transformation des structures productives de ces économies conduit à une appréciation du taux de change réel d'équilibre, la politique de change doit tenter de limiter les cycles de surévaluation et de sous-évaluation autour de cette tendance. Dans cette perpective, il serait sans doute néfaste de se donner comme un objectif de rejoindre à marche forcée la norme très basse d'inflation des pays de l'UEM. L'inflation dans les pays étudiés est fermement sous contrôle. Mais elle doit rester à un niveau qui est compatible avec un équilibre épargneinvestissement capable d'engendrer un autofinancement suffisant des entreprises pour ne pas dépendre excessivement des entrées de capitaux. C'est pourquoi la politique de change doit piloter le taux de change réel de manière que la profitabilité des entreprises soit préservée. Il revient à la politique budgétaire et, si possible, à une politique des revenus de maîtriser l'évolution de la demande intérieure pour régulariser le rythme de l'accumulation du capital. 


\section{RÉFÉRENCES BIBLIOGRAPHIQUES}

AGENOR PR. et HOFFMAISTER A. W., [1996] "Capital inflows and th real exchange rate : analytical framework and econometric evidence", IMF Working Paper, $\mathrm{n}^{\circ} 137$, décembre.

BEGG D., [1997] "Monetary policy during transition : progress ans pitfalls in central and Eastern Europe, 1990-96", Oxford Review of Economic Policy, vol 13, n², 1997, p 33-46.

BAUlant C. [1988] "Taux de change réels, niveaux d'industrialisation et normes de change", Thèse de doctorat, Paris X, décembre.

Baulant C., [1998-a] "Les taux de change de la Hongrie, la Pologne et la République tchèque sont -ils compétitits ?", Document de travail Banque de France, DGSE-ChangesSAMI, n98-71, mars.

BENASSY-QUÉrÉ A., et LARHRECHE-REVIL A., [1998] "Pegging the CEECs Currencies to the Euro", Document de travail CEPII, mai.

BLAHA J [1996] "L'économie tchèque en 1995-1996 : une croissance modèle", Le Courrier des pays de l'Est, $\mathrm{n}^{\circ} 409$, mai-juin.

CALVO GA., REINHART CM. et VEGH CA., [1995] "Targeting the real exchange rate : theory and evidence", Journal of Development economics, vol 47, $\mathrm{n}^{\circ} 1$, juin, p 93-134.

CORDEN M., [1994] "Exchange Rate policy in developing countries", Approaches to exchange rate policy, IMF Institute, pp 65-89.

DEUTSCHE MORGAN GRENFELL [1997] "Over or Undervalued? The PPP approach for East European currencies", Emerging market, 25 novembre.

EDWARD S., [1994] "Exchange Rate misalignment in developing countries", Approaches to exchange rate policy, IMF Institute, pp 45-64.

GHOST A., GULDE AM., OSTRY J. et WOLF H., [1996] "Does the exchange rate regime matter for inflation and growth ? ", Economic Issues, $n^{\circ} 2$, IMF, pp 1-12.

GOLDBER G. PK and KeTTER M., [1997] "Goods prices and exchange rates : what have we learned ? ", Journal of Economic Literature, vol XXXV, septembre, pp 1243-1272.

GRAFE C. et WYPLOSZ C., [1997] "The real exchange rate in transition economies", CEPR Discussion Paper Series, ${ }^{\circ} 1773$, décembre.

HALPERN L., [1996] "Real exchange rates and exchange rate policy in Hungary", CEPR Discussion Paper Series, $\mathrm{n}^{\circ} 1366$, mars. 
HALPERN L. et WYPLOSZ C., [1996] "Equilibrium exchange rates in transition economies", IMF Working Paper, $\mathrm{n}^{\circ} 125$.

KRAJNYAK K., and ZETTELMEYER J., [1997] "Competitiveness in Transition Economies : What Scope for Real Appreciation ?" IMF Working Paper, WP/97/149, november.

MEUNIER N., [1998] "Europe centrale et crise asiatique : pas de contagion, mais attention aux répercussions", , $\mathrm{CDC}, \mathrm{n}^{\circ} 98-05,02$ mars.

OBSTFELD M., [1995] "International currency experience : new lessons and lessons relearned", Brookings Papers on Economic Activity, n¹,pp119-219.

OCDE, [1997] Perspectives Economiques de l'OCDE, décembre.

OCDE, [1998] Perspectives Economiques de l'OCDE, juin.

OCDE, [1996] Etudes économiques de l'OCDE 1995-1996 : La République tchèque.

OCDE, [1997] Etudes économiques de l'OCDE 1996-1997 : Pologne

OCDE, [1997] Etudes économiques de l'OCDE 1996-1997 : Hongrie.

OCDE, [1995] Etudes économiques de l'OCDE 1995 : Hongrie.

STERNE G ED., [1997] "Monetary policy in transition : the case of centra Europe", Central Banking, $\mathrm{n}^{\circ} 1$, Bank of England, été. 
ANNEXES

ANNEXE 1 : MÉTHODE DE CALCUL DU TAUX DE CHANGE RÉEL EN NIVEAU POUR LES PAYS DE L'EST

\section{1) Taux de change réel en niveaux : écarts des taux de change à la PPA absolue}

Pour résoudre les problèmes du choix de l'année de base, un des moyens consiste à calculer pour cette année l'écart des niveaux de prix par rapport à la PPA absolue.

Pour cela, on corrige les niveaux des prix de l'année de base (100 par hypothèse dans tous les pays) par l'écart qui existait, pour cette année, entre le niveau du taux de change courant et le taux de conversion des monnaies (appelé "taux de PPA"). Ce taux de PPA assure, par construction l'égalité des pouvoirs d'achat des monnaies pour l'année de base.

Ces taux de PPA sont calculés à partir des enquêtes de prix de l'ONU ou d'Eurostat qui relèvent dans différents pays du monde les prix d'un même panier de biens et services. Le taux de PPA mesure l'écart entre les prix pratiqués dans les différents pays du monde et le prix mondial de chaque bien et service calculé en faisant la moyenne des prix relevés.

A partir des taux de change réels calculé en niveaux, on peut alors calculer le taux de PPA absolu de chaque monnaie qui assurerait l'égalité des pouvoirs d'achat des monnaies et donc l'égalité des niveaux de prix.

\section{2) Calculs des taux de change réels en niveaux}

Le taux de change réel en niveau rapporte le taux de change courant au taux de change de PPA calculé pour le PIB.

Les taux de PPA du PIB sont extraits de la Base chelem PIB.

La base CHELEM-PIB, du CEPII, propose des données de PIB en dollars et de PIB PPA sur longue période et pour un grand nombre de pays.

Les données fournies par cette base sont annuelles et disponibles jusqu'en 1997 pour les pays de l'OCDE et 1996 pour les autres pays.

Les PIB PPA sont issues du projet de comparaisons internationales.

Pour les pays ne participant pas à l'enquête, les PPA sont extrapolés en fonction du $\mathrm{PIB} /$ tête des économies. 
La base Chelem propose ainsi des données reposant sur la dernière enquête de prix disponible : 
- 1993 pour l'OCDE (méthode d'agrégation EKS et GK) et l'Afrique (méthode GK), - 1990 pour l'Europe de l'Est (approche binaire et par rapport à l'Autriche ${ }^{20}$ )

Pour les pays de l'Est un traitement particulier a été nécessaire en raison de la déconnexion de ces économies par rapport aux marchés mondiaux, et en raison d'une comptabilité nationale fondée sur le produit matériel net. Ce sont les travaux des économistes spécialisés du CEPII qui ont permis la construction des séries de données pour la Hongrie, la Pologne, la République tchèque, la Slovaquie, la Bulgarie, la Roumanie, l'ex-URSS et la Chine.

Pour les autres pays, l'estimation des données de PIB PPA s'effectue en deux étapes. La première consiste à calculer un niveau moyen de prix pour chaque zone, à partir des pays couverts par les enquêtes du PCI.

Dans la seconde étape, on établit la situation de chaque pays manquant dans la zone, par rapport à ce niveau moyen de prix sur une base pluriannuelle (11 ans), et compte tenu de la relation de long terme entre niveaux de prix du PIB et PIB par tête en PPA.

L'ensemble des pays estimés selon cette méthode ne représentait que 5,6\% du PIB mondial en PPA de 1992 (85 pays concernés dans la base 1990).

\footnotetext{
${ }^{20}$ Pour la Hongrie et la Pologne, il y a d'abord eu des comparaisons binaires par rapport à l'Autriche, puis ces pays ont été intégrés au programme de comparaison européen grâce à la méthode GearyKhamis;
} 
ANNEXE 2 : MÉTHODE DE CALCUL DU TAUX DE CHANGE RÉEL EN ÉVOLUTION POUR LES PAYS DE L'EST

\section{1) Taux de change réels en évolution: écarts des taux de change à la loi du prix unique relative}

Il existe deux grandes définitions du taux de change réel, utilisées alternativement par les économistes pour analyser la compétitivité-prix des pays. Selon une première définition, généralement utilisée pour analyser la situation des pays en transition, le taux de change réel mesure les prix relatifs des biens domestiques par rapport aux biens échangeables :

$$
\text { q1 }=\text { PN/PT }
$$

Cette définition du taux de change réel est utile pour analyser la compétitivité des pays en transition connaissant une forte restructuration de leur système industriel. Une hausse du taux de change réel rend compte d'une évolution plus rapide des prix du secteur domestique que ceux du secteur exposé à la concurrence internationale et traduit ainsi une réallocation des ressources productives vers le secteur domestique.

Selon une seconde définition, la plus utilisée, le taux de change réel mesure les prix relatifs des biens échangeables entre deux ou plusieurs pays.

$$
\text { q2 }=\text { PT/PT* } * \text { e }
$$

Une hausse du taux de change réel traduit une évolution plus rapide des prix du secteur exposé du pays étudié par rapport à ceux des pays concurrents, lorsque ceux-ci sont convertis en monnaie commune par le taux de change e.

Compte tenu de la structure en transition des économies étudiées, nous avons retenu l'une et l'autre définition du taux de change réel. La première définition a été utilisée en calculant le rapport des prix à la consommation sur les prix de production ou sur les prix de l'investissement. Ces deux indicateurs peuvent être considérés comme deux proxy du taux de change réel interne (prix du secteur abrité sur prix du secteur exposé). La seconde définition du taux de change réel a été utilisée en calculant cet indice sur un indice de coût (les coûts salariaux unitaires) et sur plusieurs indices de prix (prix à la consommation, prix d'exportation des biens et prix d'exportation des produits manufacturés) 21 .

L'étude de la compétitivité-prix d'un pays repose sur le calcul du taux de change réel qui permet de comparer l'évolution des prix entre deux ou plusieurs pays.

\section{2) Calcul des taux de change réels en évolution}

L'étude de la compétitivité-prix d'un pays repose sur le calcul du taux de change réel qui permet de comparer l'évolution des prix entre deux ou plusieurs pays.

Pour les trois pays étudiés, nous avons calculé des taux de change réels effectifs établis par rapport aux 10 principaux pays partenaires de ces pays, en utilisant une pondération

${ }^{21}$ Nous avons utilisé les "Prévisions économiques de l'OCDE" de décembre 1997. 
fondée sur le commerce total (exportations plus importations de biens) de ces pays (tableau ci après).

Pour construire cet indice de taux de change réel, nous avons retenu les exportations de biens vers les pays de $\mathrm{l}^{\prime} \mathrm{OCDE}^{22}$. Ces pays, et l'Union européenne en particulier, représentent les principaux pays partenaires des économies de l'Europe de $\mathrm{l}^{\prime} \mathrm{Est}^{23}$.

Nous avons retenu les 10 principaux pays partenaires communs aux trois pays étudiés.

Par ailleurs, il n'a pas été possible de calculer une "double pondération à l'exportation" qui tiennent compte, non seulement la part relative des produits exportés par les pays d'Europe de l'Est sur le marché mondial,

Néanmoins, la comparaison des indices de taux de change réels effectifs calculés avec les prix à la consommation avec ceux établis par le FMI avec une double pondération à l'exportation donne des résultats voisins pour la Hongrie et la Pologne (Baulant [1998a]).

Par exemple, pour la Hongrie, le taux de change effectif nominal du forint contre les 10 monnaies des principaux pays partenaires de la Hongrie se définit ainsi :

où

$$
\operatorname{TCEN}_{\text {hong }}=\underset{j 00 \times \prod\left(E_{j}\right){ }^{w x} x_{j}}{j=1}
$$

$\mathrm{E}_{\mathrm{j}}$ : désigne le taux de change à l'incertain de chaque monnaie des $\mathrm{j}$ pays par rapport au forint, calculé en indice par rapport à l'année 1994=1. Une appréciation du forint se traduit donc une augmentation de TCEN ${ }_{\text {hong }}$.

$\Pi$ : la moyenne géométrique ;

$\mathrm{wx}_{\mathrm{j}}$ : est la pondération des différents pays $\mathrm{j}$ dans le commerce de la Hongrie.

Pour la Hongrie, le taux de change effectif réel des prix ou des coûts s'écrit :

$$
\text { TCRE }_{\text {hong }}=\frac{\mathbf{P}_{\text {hong }}}{\left.\prod_{\substack{10 \\ \mathbf{j}=\mathbf{1}}} \mathbf{P}_{\mathbf{j}}\right)^{\mathbf{w x j}}} \text { TCEN }_{\text {hong }}
$$

22 Nous avons utilisé les "séries A de l'OCDE" qui donnent la répartition géographique du commerce de chaque pays de l'OCDE.

23 Les pays de l'Union européenne (hors Royaume-Uni) représentaient en 1995 plus de 80\% du commerce (exportations plus importations) des trois pays d'Europe de l'Est. La République tchèque effectue cependant plus de $10 \%$ de son commerce avec la Pologne. 


\section{où $\mathrm{P}_{\mathrm{j}} \quad$ désigne l'indice de prix ou de coût du pays $\mathrm{j}$.}

Une hausse du taux de change réel effectif de la Hongrie correspond à une appréciation du forint ou une détérioration de la compétitivité prix ou coût de la Hongrie. 
POIDS DES PAYS PARTENAIRES

DANS LE COMMERCE EXTERIEUR DES PAYS DE L'EST

\begin{tabular}{|c|c|c|c|c|}
\hline & Hongrie & $\begin{array}{c}\text { Commerce total } \\
\text { (export. }+ \text { import. })\end{array}$ & Exportations & Importations \\
\hline 1 & Allemagne & 45,92 & 47,57 & 44,41 \\
\hline 2 & Autriche & 15,83 & 12,2 & 19,15 \\
\hline 3 & Italie & 12,62 & 12,48 & 12,74 \\
\hline 4 & France & 5,5 & 5,22 & 5,76 \\
\hline 5 & Royaume-Uni & 4,96 & 5,77 & 4,22 \\
\hline 6 & Pays-Bas & 4,25 & 3,99 & 4,48 \\
\hline 7 & Belgique & 4,03 & 3,9 & 4,15 \\
\hline 8 & États-Unis & 3,97 & 5,39 & 2,67 \\
\hline 9 & Pologne & 2,92 & 3,48 & 2,42 \\
\hline & Total & 100 & 100 & 100 \\
\hline
\end{tabular}

\begin{tabular}{|c|l|c|c|c|}
\hline & Pologne & $\begin{array}{c}\text { Commerce total } \\
\text { (export. }+ \text { import. })\end{array}$ & Exportations & Importations \\
\hline 1 & Allemagne & 52,32 & 57,79 & 47,88 \\
\hline 2 & Italie & 11,12 & 8,14 & 13,54 \\
\hline 3 & Royaume-Uni & 7,44 & 6,70 & 8,03 \\
\hline 4 & France & 7,28 & 6,87 & 7,61 \\
\hline 5 & Pays-Bas & 6,96 & 6,37 & 7,43 \\
\hline 6 & Belgique & 4,62 & 3,85 & 5,24 \\
\hline 7 & États-Unis & 4,29 & 4,42 & 4,19 \\
\hline 8 & Autriche & 4,24 & 4,21 & 4,26 \\
\hline 9 & Hongrie & 1,75 & 1,65 & 1,82 \\
\hline & Total & 100 & 100 & 100 \\
\hline
\end{tabular}

\begin{tabular}{|c|l|c|c|c|}
\hline & $\begin{array}{c}\text { République } \\
\text { tchèque }\end{array}$ & $\begin{array}{c}\text { Commerce total } \\
\text { (export.+import.) }\end{array}$ & Exportations & Importations \\
\hline 1 & Allemagne & 52,52 & 54,30 & 51,02 \\
\hline 2 & Pologne & 10,66 & 13,09 & 8,62 \\
\hline 3 & Autriche & 9,51 & 9,16 & 9,81 \\
\hline 4 & Italie & 7,18 & 5,99 & 8,18 \\
\hline 5 & France & 4,87 & 3,51 & 6,02 \\
\hline 6 & Royaume-Uni & 4,72 & 3,76 & 5,53 \\
\hline 7 & Pays-Bas & 3,20 & 2,65 & 3,67 \\
\hline 8 & Belgique & 2,98 & 2,20 & 3,63 \\
\hline 9 & États-Unis & 2,44 & 2,67 & 2,24 \\
\hline 10 & Hongrie & 1,92 & 2,67 & 1,28 \\
\hline & Total & 100 & 100 & 100 \\
\hline
\end{tabular}

Source : OCDE A, calculs Banque de France, DGSE-SAMI, Ch. Courtin.

Réalisation : Banque de France, DGSE-SAMI, C. Baulant. Mise à jour le 25 mars 1998. 


\section{LISTE DES DOCUMENTS DE TRAVAIL DU CEPII ${ }^{24}$}

\section{8}

"Sensibilité des salaires relatifs aux chocs exogènes de commerce international et de progrès technique : une élévation d'équilibre général", Sébastien Jean, Olivier Bontout, document de travail $n^{\circ} 98-09$, septembre.

"Evolution sur longue période de l'intensité énergétique", Pierre Villa, document de travail $n^{\circ} 98-08$, septembre.

"Sacrifice Ratios in Europe: a Comparison", Laurence Boone, Benoît Mojon, document de travail $n^{\circ} 98-07$, août.

"La politique japonaise et la crise monétaire", Stéphanie Guichard, document de travail $n^{\circ} 98-06$, juillet.

"La régionalisation du commerce international : une évaluation par les intensités relatives bilatérales", Michaël Freudenberg, Guillaume Gaulier, Deniz Ünal Kesenci, document de travail $n^{\circ} 98-05$, juillet.

"Pegging the ceec's currencies of the euro", Agnès Bénassy-Quéré et Amina LahrècheRévil, document de travail $n^{\circ} 98-04$, juillet.

"The international role of the euro", Agnès Bénassy-Quéré, Benoît Mojon, Armand-Denis Schor, document de travail $n^{\circ} 98-03$, mars.

"EMU and Transatlantic Exchange Rate Stability", Agnès. Bénassy Quéré et Benoît. Mojon, document de travail $n^{\circ} 98-02$, avril.

"Programme de travail 1998", Jean-Claude Berthélemy, document de travail n98-01, avril.

\section{7}

"Why the Euro Will Be Strong : an Approach Based on Equilibrium Exchange Rates", Michel Aglietta, Camille Baulant, Virginie Coudert, document de travail $n^{\circ}$ 97-18, décembre.

"How foreing Direct Investment Affects International Trade and Competitiveness. An Emppirical Assessment", Lionel Fontagné, Mickaël Pajot, document de travail $n^{\circ}$ 97-17, décembre.

"Cycles de production industrielle : une analyse historique dans le domaine des fréquences", Pierre Villa document de travail $n^{\circ} 97-16$, novembre.

"International and External Policy Coordination: a Dynamic Analysis", Fabrice Capoën,

\footnotetext{
24 Les documents de travail sont diffusés gratuitement sur demande dans la mesure des stocks disponibles. Merci d'adresser votre demande au CEPII, Sylvie Hurion, 9, rue Georges Pitard, 75015 Paris ou par fax :+33 153685503 ou par e-mail : HURION@CEPII.FR.
} 
Pierre Villa, document de travail $n^{\circ} 97-15$, octobre. 
"Optimal Pegs for Asian Currencies", Agnès Bénassy-Quéré, document de travail $n^{\circ}$ 9714 , octobre.

"Pour ou contre le système commun de TVA?", Stéphanie Guichard, Claire Lefèbvre, document de travail $n^{\circ}$ 97-13, juin.

"The Euro and Exchange Rate Stability", Agnès Bénassy-Quéré, B. Mojon, Jean PisaniFerry, document de travail $n^{\circ} 97-12$, juin.

Estimation du cycle à l'aide d'un modèle à tendance stochastique et application au cas du Royaume-Uni", Laurence Boone, document de travail $n^{\circ}$ 97-11, juin.

"Looking for French Monetary Policy", Benoît Mojon, document de travail $n^{\circ}$ 97-10, juin.

"Incertitude sur le choix du modèle et rationalité", Pierre Villa, document de travail $n^{\circ}$ 9709, mai.

"Quel est l'impact du commerce extérieur sur la productivité et l'emploi ?", Olivier Cortes, Sébastien Jean, document de travail $n^{\circ}$ 97-08, avril

"Trade Patterns Inside the Single Market" Lionel Fontagné, Michael Frendenberg \& Nicolas Péridy, document de travail $n^{\circ}$ 97-07, avril.

"The Exchange Rate Policy of the Euro: A Matter of Size", Philippe Martin, document de travail $n^{\circ}$ 97-06, avril.

"Ces taux de change réels qui bifurquent", Pierre Villa, document de travail $n^{\circ}$ 97-05, avril.

"Chômage non-qualifié et imitation : les raisons d'un accord international sur la propriété intellectuelle", Lionel Fontagné \& Jean-Louis Guérin, document de travail $n^{\circ}$ 97-04, mars.

Symmetry and Asymmetry of Supply and Demand Shocks in the European Union a Dynamic Analysis", Laurence Boone, document de travail n 97-03, février.

"Interest Rates in East Asian Countries: Internal Financial Structures and International Linkages", Isabelle Bensidoun, Virginie Coudert et Laurence Nayman, document de travail $n^{\circ}$ 97-02, janvier.

"Intra-Industry Trade: Methodological Issues Reconsidered", Lionel Fontagné, Michael Freudenberg, document de travail $n^{\circ}$ 97-01, janvier. (épuisé) 


\section{6}

"The Cost of Fiscal Retrenchment Revisited: How Strong is the Evidence?", Philippine Cour, Eric Dubois, Selma Mahfouz \& Jean Pisani-Ferry, document de travail $n^{\circ}$ 96-16, décembre.

"Les dynamiques sectorielles de la croissance en Europe centrale", Françoise Lemoine, document de travail 96-15, décembre.

"Growth and Agglomeration", Philippe Martin \& Gianmarco I.P. Ottaviano, document de travail $n^{\circ}$ 96-14, décembre.

"La coordination interne et externe des politiques économiques: une analysee dynamique", Fabrice Capoen et Pierre Villa, document de travail $n^{\circ}$ 96-13, décembre.

"L'intégration asymétrique au sein du continent américain : un essai de modélisation", Philippine Cour et Frédéric Rupprecht, document de travail $n^{\circ}$ 96-12, octobre.

"Croissance et contrainte financière dans les PED", Pierre Villa, document de travail $n^{\circ}$ 96-11, octobre.

"Bulgaria From Entreprise Indiscipline to Financial Crisis", Roumen Avramov et Jérôme Sgard, document de travail $n^{\circ} 96-10$, juillet.

"Potentialities and Opportunities of the Euro as an International Currency", Agnès Bénassy-Quéré, document de travail n 96-09, août.

"Credit Crisis and the Role of Banks During Transition: a Five-Country Comparison", Jérôme Sgard, document de travail $n^{\circ}$ 96-08, août.

"Exchange Rate Regimes and Policies in Asia", Agnès Bénassy-Quéré, document de travail $n^{\circ}$ 96-07, juillet.

"France in the Early Depression of the Thirties", Pierre Villa, document de travail $n^{\circ}$ 96-06, juillet.

"Pays émergents, emploi defficient ?", Olivier Cortès et Sébastien Jean, document de travail $n^{\circ}$ 96-05, mars.

"Trade with Emerging Countries and the Labor Market: the French Case", Olivier Cortès, Sébastien Jean et Jean Pisani-Ferry, document de travail $n^{\circ}$ 96-04, mars.

"The Transmission of Monetary policy in the European Countries", Fernando Barran, Virginie Coudert et Benoit Mojon, document de travail $n^{\circ}$ 96-03 , février. 
"Trade Policy and Trade Patterns During Transition: A Comparison Between China and CEECs", Françoise Lemoine, document de travail $n^{\circ}$ 96-02, février.

"Financial Markets Failures and Systemic Risk", Michel Aglietta, document de travail $n^{\circ}$ 96-01, janvier

\section{5}

"Why NAFTA Might be Discriminatory", Lionel Fontagné, document de travail $n^{\circ}$ 95-12, décembre.

"Régionalisation et échanges de biens intermédiaires", Lionel Fontagné, Michael Freudenberg et Deniz Ünal-Kesenci, document de travail $n^{\circ}$ 95-11, décembre.

"The Geography of Multi-speed Europe", Philippe Martin et Gianmarco I.P Ottaviono, document de travail $n^{\circ} 95-10$, novembre.

"The Political Economy of French Policy and the Transmission to EMU", Christian de Boissieu et Jean Pisani-Ferry, document de travail $n^{\circ}$ 95-09, octobre (épuisé).

"L'importance des exclus de l'intégration monétaire en Europe", Philippe Martin, document de travail $n^{\circ}$ 95-08, novembre.

"Asymétries financières en Europe et transmission de la politique monétaire", Virginie Coudert et Benoit Mojon, document de travail $n^{\circ}$ 95-07, septembre (épuisé).

"La mesure du capital éducatif", Pierre villa, document de travail n 95-06, septembre.

"Capital humain, mobilité des capitaux et commerce international", Pierre Villa, document de travail $n^{\circ} 95-05$, juin.

"L'Europe à géométrie variable : une analyse économique", Jean Pisani-Ferry, document de travail $n^{\circ}$ 95-04, avril.

"Comparaison de l'efficacité énergétique des pays d'Europe centrale et orientale avec celle des pays de l'OCDE", Nina Kounetzoff, document de travail $n^{\circ}$ 95-03, mars.

"L'organisation de la politique économique dans un cadre stratégique", Pierre Villa, document de travail $n{ }^{\circ} 95-02$, mars.

"Interest Rates, Banking, Spreads and Credit Supply: The Real Effects", Fernando Barran, Virginie Coudert, Benoît Mojon, document de travail n 95-01, mars. 
Graphique 3-A : taux de change effectifs des trois pays de l'Est calculés pour les coûts salariaux unitaires

et les prix d'exportation

Base $1994=1$
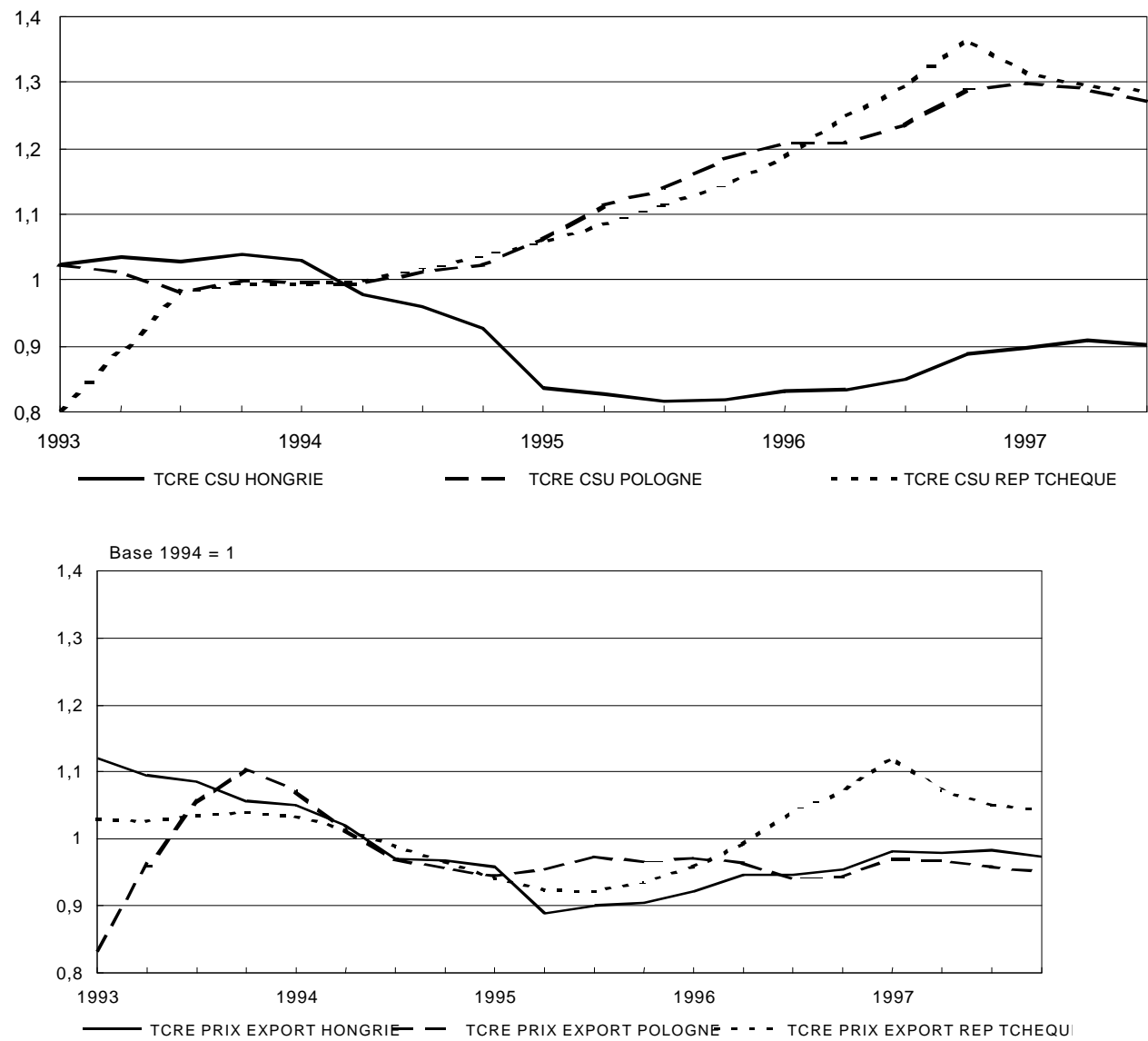


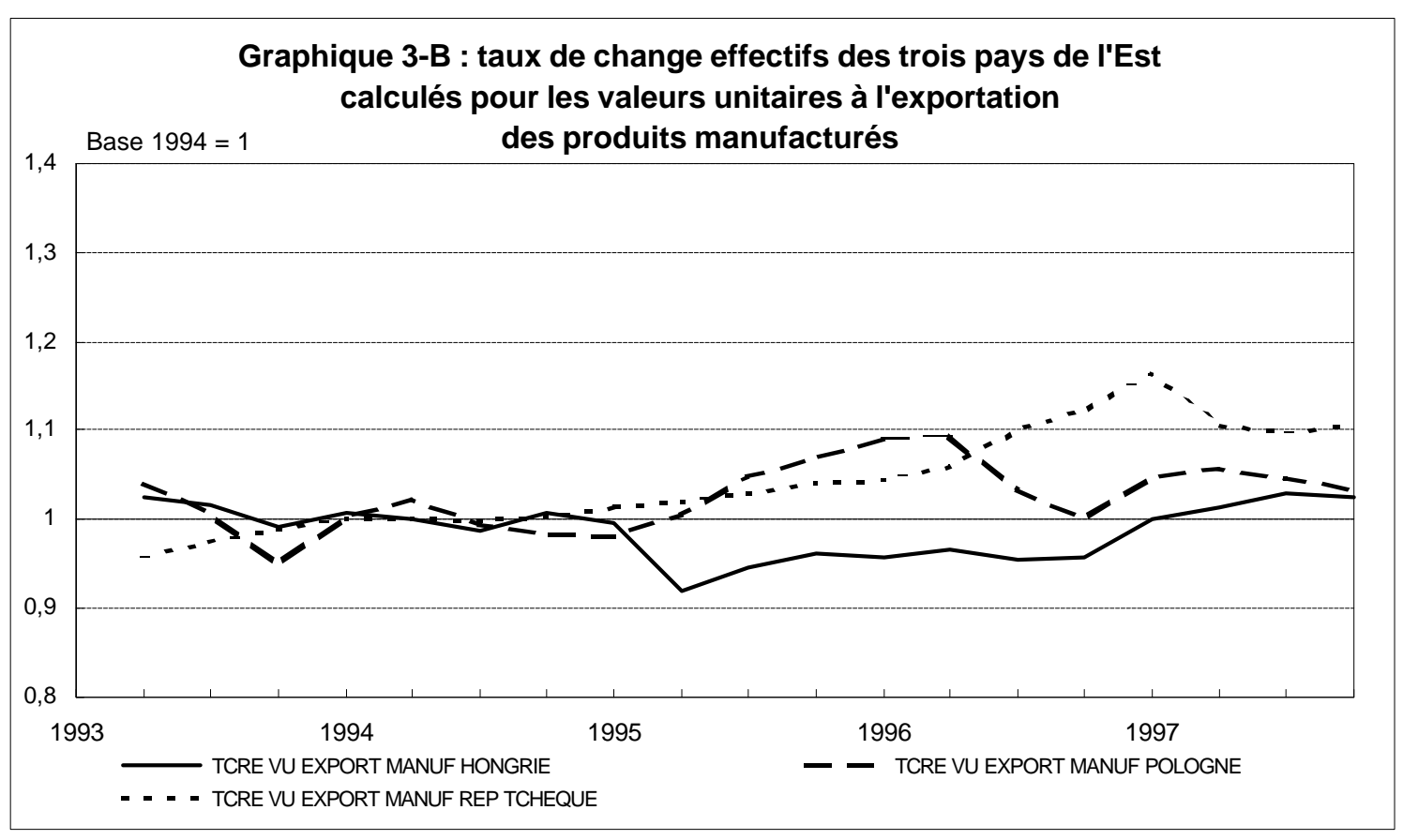

